\title{
Lysine-Functionalized Layered Double Hydroxides For The Antibiotics' Efficient Removal: Controllable Fabrication Via BBD Model And Removing Mechanism
}

Yuying Hu ( $\nabla$ huyuying@foxmail.com )

East China JiaoTong University

Susu Liu

East China JiaoTong University

Min Qiu

East China JiaoTong University

Xiaohuan Zheng

East China JiaoTong University

Xiaoming Peng

East China JiaoTong University

Hongling Dai

East China JiaoTong University

Fengping Hu

East China JiaoTong University

Li Xu

Jiangxi Province Key Laboratory of Drinking Water Safety

GaoPing Xu

Jiangxi Province Key Laboratory of Drinking Water Safety

\section{Research Article}

Keywords: Antibiotics, LDHs, Lysine, Box-Behnken Design, Adsorption mechanism

Posted Date: December 20th, 2021

DOI: https://doi.org/10.21203/rs.3.rs-1115746/v1

License: (a) (1) This work is licensed under a Creative Commons Attribution 4.0 International License. Read Full License 


\section{Abstract}

Ly @ FeZn layered double hydroxides (LDHs) controllable fabrication based on Box-Behnken Design (BBD) model was fabricated, and presented stable and efficient removal performance for Ciprofloxacin (CIP), Norfloxacin (NOR) and Ofloxacin (OFL) removal. It should be noted that Ly @ FeZn had different adsorption behavior towards CIP, NOR and OFL. Furthermore, the Ly @ FeZn was characterized by SEM, XRD, FT-IR and XPS. Results revealed the optimized fabrication condition (temperature of $60{ }^{\circ} \mathrm{C}, \mathrm{Fe} / \mathrm{Zn}$ molar ratio of 0.5 and the lysine dosage of $5.8 \mathrm{mmol}$ ) for the removing efficient. The highest adsorption capacity of CIP, NOR and OFL were $193.83,190.20$ and $62.12 \mathrm{mg} / \mathrm{g}$, respectively. Adsorption kinetics of both CIP and NOR were well simulated with the pseudo-first-order kinetic model, while that of OFL was well-described by the pseudo-second-order. Moreover, the adsorption thermodynamics of CIP and NOR on Ly @ FeZn indicated that the adsorption processes were exothermal, feasible and spontaneous. It was worth noting that the adsorption mechanism of Ly @ FeZn for CIP and NOR were the synergistic reaction of electrostatic attraction, chemical bonding and flocculation. On the other side, the adsorption behavior of OFL was relatively low, and the adsorption mechanism was only electrostatic attraction.

\section{Introduction}

Recently, the increasing use of pharmaceuticals and personal care products has led to widespread discharge of such products into water environment. Since these products pose a potential threat to the water environment and human health, this issue has attracted attention. CIP, NOR and OFL are fluoroquinolone antibiotics widely used as veterinary and human drugs. It offers high antibacterial activity against Gram negative and Gram positive bacteria by inhibiting DNA gyrase [Fang et al. 2020]. CIP, NOR, OFL antibiotics can be found in animal husbandry, hospital wastewater and sewage treatment plants. Therefore, it is imperative to develop an effective method to remove antibiotics in wastewater. Commonly used methods for removing antibiotics include adsorption [Chen et al. 2015, Fang et al. 2020], membrane filtration [Azhar et al. 2017, Koyuncu et al. 2008], catalysis [Chen et al. 2019] and photocatalytic degradation [Hu et al. 2019]. However, membrane filtration is high cost and prone to cause membrane fouling [Azhar et al. 2017]. Photocatalysis and catalytic degradation may decompose antibiotics into small molecules. In addition, the cost of catalysts is a constraint for large-scale application, and it is difficult to determine the harmfulness of by-products of catalysts [Mehrjouei et al. 2014]. Compared with other treatment methods, adsorption has been considered to be a more effective method to remove contaminants in aqueous systems [Yan et al. 2017]. Referring to the recent studies, various materials are used as adsorbents to remove fluoroquinolones from wastewater, such as natural mineral materials [Jiang et al. 2013] and carbonbased materials [Carabineiro et al. 2012, Wang et al. 2011] for CIP removal; barley straw [Yan et al. 2017], porous resin and carbon nanotubes [Yang et al. 2012] have also been utilized for NOR adsorption; similarly, mesoporous alumina, cork-bio-mass and silica have been investigated [Crespo-Alonso et al. 2013] for OFL adsorption. However, the removal efficiency of these traditional adsorbents for antibiotics remains to be improved. Therefore, the development of renewable adsorbents with high adsorption capacity has been widely studied.

Amino acid can be used to remove contaminants in water environment because of its good chelation [Koilraj et al. 2019]. In order to achieve high efficiency and stability, amino acids are considered to be functionalized on solid surfaces with excellent properties. There are some reports on the contaminants removal by amino acid functionalized adsorbents in the literature. Glycine functionalized europium hydroxide [Alemtsehay et al. 2018] and arginine modified hydroxyapatite [Yang et al. 2017] were used to remove radioactive elements in wastewater. Similarly, $\mathrm{FeSO}_{4}$ grafted lysine modified polymer [Jing et al. 2018] and arginine and lysine functionalized $\mathrm{Fe}_{3} \mathrm{O}_{4}$ [Singh et al. 2016, Zhang et al. 2014] have been developed to remove organic matter, $\mathrm{Ni}(\mathrm{I})$ and arsenate [Jing et al. 2018, Singh et al. 2016, Zhang et al. 2014]. These reports showed that amino acid functionalized materials are multifunctional adsorbent, and the treatment effect of wastewater containing pollutants is considerable.

Layered double hydroxides ( $\mathrm{LDHs}$ ) are synthetic clays, whose molecular formula is $\left[\mathrm{M}(\mathrm{II})_{1-\mathrm{x}} \mathrm{M}(\mathrm{III})(\mathrm{OH})_{2}\right]^{\mathrm{x}+}\left(\mathrm{A}^{\mathrm{n}-}\right)_{\mathrm{x} / \mathrm{m}} \cdot \mathrm{mH}_{2} \mathrm{O}$, where $\mathrm{M}$ (II), $M$ (III) and $A^{n-}$ are divalent and trivalent metal ions and interlayer charge equilibrium anions, respectively. Because of their high surface area, exchangeable anions, low cost and non-toxic properties, LDHs is condemned as a promising adsorbent to remove heavy metals and organic compounds (including dyes, pharmaceuticals and personal care products) in water treatment. Therefore, it is considered to functionalize amino acids on LDHs to achieve better adsorption performance. 
Amino acid functionalized LDHs are used to remove different types of pollutants. A-alanine functionalized MgFe-LDH [Hong et al. 2014], glycine functionalized MgAl-LDH [Asiabi et al. 2017] and histidine functionalized MgAl-LDH [Tran et al. 2018] have been reported to be used to remove oxygen anions, heavy metal cations and organic compounds. Compared with the LDHs reported in other literature, the prepared amino acid functionalized LDHs have higher removal capacity. Based on these observations, we studied the effect of lysine-functionalized LDHs for the antibiotics' efficient removal in aqueous systems.

As far as we know, there is no report about amino acid functionalized LDHs adsorption for antibiotics. In this study: (1) the controllable preparation of Ly @ FeZn was optimized by RSM. It means an efficient RSM model was established with the least number of experiments. Then, high adsorption capacity adsorbent was prepared at low cost. By the response surface optimization analysis, the $\mathrm{q}_{\mathrm{e}}$ for CIP could reach the highest $(202 \mathrm{mg} / \mathrm{g})$ at temperature of $60^{\circ} \mathrm{C}$, Fe / Zn molar ratio of 0.5 and the lysine dosage of $5.8 \mathrm{mmol}$. (2) the optimized Ly @ FeZn was characterized by SEM, XRD, FT-IR and XPS. Batch technique (including adsorbent dosage, $\mathrm{pH}$, contact time, antibiotic concentration and temperature) were performed. The results showed that the removal rate of CIP and NOR by Ly @ FeZn was above 95\%. Moreover, different removal mechanism of Ly @ FeZn for CIP, NOR and OFL was investigated.

\section{Materials And Methods}

\subsection{Chemicals}

Ferric nitrate $\left(\mathrm{Fe}\left(\mathrm{NO}_{3}\right)_{3} \cdot 9 \mathrm{H}_{2} \mathrm{O}\right.$, Analytical reagent, 98.5\%), Zinc nitrate $\left(\mathrm{Zn}\left(\mathrm{NO}_{3}\right)_{2} \cdot 6 \mathrm{H}_{2} \mathrm{O}\right.$, Analytical reagent, $\left.99 \%\right)$, Sodium hydroxide $(\mathrm{NaOH}, 1 \mathrm{M}$, Analytical reagent), L-Lysine was purchased from Shanghai Macklin Biochemical Co.Ltd. All the above chemicals used in this study were analytically pure.

\subsection{Synthesis of Ly @ FeZn}

Ly @ FeZn was synthesized by hydrothermal method. Specifically, $3 \mathrm{mmol}$ of Fe( $\left(\mathrm{NO}_{3}\right)_{3} \cdot 9 \mathrm{H}_{2} \mathrm{O}$, and $6 \mathrm{mmol} \mathrm{Zn}\left(\mathrm{NO}_{3}\right)_{2} \cdot 6 \mathrm{H}_{2} \mathrm{O}($ the initial molar ratio of $\mathrm{Fe}\left(\mathrm{NO}_{3}\right)_{3} \cdot 9 \mathrm{H}_{2} \mathrm{O} / \mathrm{Zn}\left(\mathrm{NO}_{3}\right)_{2} \cdot 6 \mathrm{H}_{2} \mathrm{O}(\mathrm{Fe} / \mathrm{Zn})$ was 0.5$)$ were dissolved in $100 \mathrm{~mL}$ deionized water. Then, $\mathrm{pH}$ was adjusted to 10 with $\mathrm{NaOH}(1 \mathrm{M})$ and the above solution was continuously stirred at $\mathrm{pH}=10$ for $10 \mathrm{~min}$. Subsequently, $5.8 \mathrm{mmol}$ of lysine was dispersed into the mixture sluggishly and stirred for $5 \mathrm{~min}$. The resulting mixture was sealed in a Teflon-lined autoclave, and then hydrothermally treated at $90^{\circ} \mathrm{C}$ for $24 \mathrm{~h}$. Afterwards, the supernatant was poured out and the solid product was separated by using centrifugation at $4000 \mathrm{rpm}$ for $3 \mathrm{~min}$. The separated solid was washed thrice with deionized water and finally dried at $60^{\circ} \mathrm{C}$ for $12 \mathrm{~h}$. The fabricated material was referred to Ly @ FeZn.

\subsection{Batch adsorption experiments}

Batch experiments were carried out under different adsorbent dosage, $\mathrm{pH}$, contact time, antibiotic concentration and temperature. In detail, $0.05 \mathrm{~g}$ of the Ly @ FeZn was added to a series of $100 \mathrm{~mL}$ Erlenmeyer flasks containing $50 \mathrm{~mL}$ CIP, NOR and OFL solution with certain concentrations. The mixed suspension was pre-equilibrated by shaking in an air thermostatic (KYC-111D, Fuma, China) shaker at $200 \mathrm{rpm}$. In addition, the $\mathrm{pH}$ value of adsorption system was adjusted with using $\mathrm{HNO}_{3}$ or $\mathrm{NaOH}$. At different time points (5-1440 min for kinetic adsorption experiment), the suspensions were filtered through 0.22-um milli-pore filter membrane. The antibiotics concentrations in aqueous solution were determined by spectrophotometer (U-90001 spectrophotometer) at maximum absorbance wavelength of 277, 275 and $293 \mathrm{~nm}$ for CIP, NOR and OFL, respectively. The adsorption capacity and removal efficiency were calculated as followings:

$$
q_{e}=\frac{\left(C_{0}-C_{e}\right) V}{m}
$$

$$
R_{e}=\frac{\left(C_{0}-C_{e}\right)}{C_{0}} \times 100 \%
$$


where $q_{e}(\mathrm{mg} / \mathrm{g})$ and $R_{e}(\%)$ were the adsorption capacity and removal efficiency respectively; $C_{0}(\mathrm{mg} / \mathrm{L})$ and $C_{e}(\mathrm{mg} / \mathrm{L})$ represented the initial and equilibrium concentrations, respectively; $V(L)$ represented the solution volume; $m(\mathrm{~g})$ was the mass of adsorbent.

\subsection{Characterization}

The surface morphology was characterized by Scanning electron microscopy (SEM, Gemini 300, Zeiss, Germany) with energy dispersive X-ray spectrometer. X-ray diffraction (XRD) pattern was recorded by XRD analysis (XRD, D8 ADVANCEX-ray diffractometer, Bruker, Germany), the sample was scanned over the region of $10-90^{\circ}$ with a $0.02^{\circ}$ step size. The composition of all samples was analyzed by X-ray photoelectron spectroscopy (XPS, ESCALAB 250XI Thermo Fisher Scientific, USA). Fourier transfer infrared (FT-IR) spectra in the wave number range of $400-4000 \mathrm{~cm}^{-1}$ was acquired with an infrared spectrometer (Nicolet 6700 , Nicolet).

\section{Results And Discussion}

\subsection{Controllable fabrication of Ly @ FeZn by RSM}

In order to fabricate an adsorbent with high adsorption capacity under the premise of low cost, the response surface model (RSM) was used to optimize the adsorbent's synthesis. The construction of RSM was for the purpose of estimating the main effects interactions, as well as establishing the efficient mathematics modeling by performing the least number of experiments [Singh et al. 2011]. RSM is a quadratic equation and a polynomial equation, which can predict the actual value of the experiment [Sen et al. 2019].

\subsubsection{Modeling set up}

BBD model was applied to study optimal conditions for preparing materials. Effects of Fe / Zn molar ratio, lysine dosage and hydrothermal treatment temperature were studied. 17 response surface model experiments were carried out by regression, and graphical analysis of the results data were analyzed with the Design-Expert software (8.0). The model consisted of three levels, coded values were $-1,0$ and 1 (low, medium, high respectively) [Yang et al. 2021]. The response value was the adsorption capacity of Ly @ FeZn for CIP. The experimental design and results were shown in Table 1.

\subsubsection{Regression model equation establishment}

The quadratic equation was obtained by predicting the optimal BBD model between the input variables and the response values. Afterwards, according to the experimental results, the empirical relationship between output variables and the response of the coding unit was given as following [Sun et al. 2019, Yang et al. 2021]:

$q_{e}=92-2.25 * A-1.88 * B-59.13 * C+0.25 * A B+1.25 * A C+3.50 *+4.25 * A^{2}-4.00 * B^{2}+43.50 * C^{2}$

3

In the equation, $\mathrm{A}, \mathrm{B}$ and $\mathrm{C}$ were denoted as the coding terms of three independent variables, namely lysine dosage, hydrothermal treatment temperature and $\mathrm{Fe} / \mathrm{Zn}$ molar ratio.

\subsubsection{Analysis of variance (ANOVA)}

Statistical analysis was performed to determine experimental error and statistical significance. In the current work, the acceptability of the model was determined by using ANOVA. The model adequacy test requires that the analysis of experimental data and the correctness of the model have to been proved via the $\mathrm{F}$ value and $\mathrm{p}$ value [Sen et al. 2019]. Referring to ANOVA (analysis of variance) in Table 1, the F-value (89.14) and P-value (< 0.0001) indicated the regression of $\mathrm{q}_{e}$ response was statistical significance. Moreover, P-value of $\mathrm{C}$ and $\mathrm{C}^{2}$ were less than 0.05 , indicating the relative model terms were significant in the model. According to the F-value, the influences of each factor were followed the order: Fe / Zn molar ratio (89.14) > Lysine dosage (0.90) > Hydrothermal reaction temperature (0.62). By the response surface optimization analysis, the $\mathrm{q}_{\mathrm{e}}$ value could reach the highest (202 $\mathrm{mg} / \mathrm{g}$ ) at temperature of $60^{\circ} \mathrm{C}, \mathrm{Fe} / \mathrm{Zn}$ molar ratio of 0.5 and the lysine dosage of $5.8 \mathrm{mmol}$. 
Table 1

ANOVA for RSM of CIP, NOR and OFL removal on Ly @ FeZn.

\begin{tabular}{|llllll|}
\hline & Sum of & & Mean & F & p-value \\
\hline Source & Squares & df & Square & Value & Prob $>$ F \\
\hline Model & 36245.87 & 9 & 4027.32 & 89.14 & $<0.0001$ \\
\hline A & 40.50 & 1 & 40.50 & 0.90 & 0.3753 \\
\hline B & 28.13 & 1 & 28.13 & 0.62 & 0.4560 \\
\hline C & 27966.13 & 1 & 27966.13 & 619.01 & $<0.0001$ \\
\hline AB & 0.25 & 1 & 0.25 & $5.534 \mathrm{E}-003$ & 0.9428 \\
\hline AC & 6.25 & 1 & 6.25 & 0.14 & 0.7209 \\
\hline BC & 49.00 & 1 & 49.00 & 1.08 & 0.3323 \\
\hline A & 76.05 & 1 & 76.05 & 1.68 & 0.2356 \\
\hline B & 67.37 & 1 & 67.37 & 1.49 & 0.2616 \\
\hline C $^{2}$ & 7967.37 & 1 & 7967.37 & 176.35 & $<0.0001$ \\
\hline Residual & 316.25 & 7 & 45.18 & & \\
\hline Lack of Fit & 316.25 & 3 & 105.42 & & \\
\hline Pure Error & 0.000 & 4 & 0.000 & & \\
\hline Cor Total & 36562.12 & 16 & & \\
\hline Note: P< 0.0001: highly significant; P $0.01:$ strongly significant; P< 0.05: significant; P> 0.05: not significant.
\end{tabular}

\subsubsection{Effects of Fe / Zn, lysine dosage and hydrothermal temperature on adsorption performance}

Figure 1a presented that the adsorption capacity of Ly @ FeZn remained at a stable level of 88-98 mg/g (Fe / Zn: 1.25, lysine dosage: $5-15 \mathrm{mmol}$, temperature: $60-120^{\circ} \mathrm{C}$ ). This suggested that hydrothermal reaction temperature and lysine dosage had limited effects on Ly @ FeZn's adsorption capacity. This may be because lysine had already been successfully loaded on the LDHs at $60^{\circ} \mathrm{C}$, and though the temperature continued to increase, the enhancement of adsorption performance was limited. On the other side, lysine dosage was saturated at $5 \mathrm{mmol}$, as it continued increased to $15 \mathrm{mmol}$, the excessive lysine will be washed off when cleaning the material. In this way, lysine dosage's effect on the adsorption capacity was limited. Fig. 1b and c indicated the Fe / Zn molar ratio was critical for the adsorption capacity. The adsorption capacity increased from $80 \mathrm{mg} / \mathrm{g}$ to $200 \mathrm{mg} / \mathrm{g}$ as the Fe / Zn molar ratio decreased from 2 to 0.5 . This suggested low Fe / Zn molar ratio was beneficial for adsorption capacity. This may be owing to the fact $\mathrm{M}^{3+}$ was only partially incorporated in the brucite-like layer because of the electrostatic repulsion between positive charges when the $\mathrm{M}^{3+} / \mathrm{M}^{2+}$ molar ratio was higher than 0.5 . At low $\mathrm{M}^{3+} / \mathrm{M}^{2+}$ ratio, $\mathrm{M}^{2+}$ occupied in the system leading to fewer anions in the interlayer, and the formation of $\mathrm{M}^{2+}$ hydroxide can be increased. This observation was similar to that of Kang's study [Kang et al. 2020].

\subsection{Characterizations}

Based on the findings in Section 3.1, subsequent materials were fabricated under the optimized conditions (temperature of $60^{\circ} \mathrm{C}$, Fe / Zn molar ratio of 0.5 and the lysine dosage of $5.8 \mathrm{mmol}$.). The XRD, FT-IR, SEM and XPS were applied to characterize the samples. XRD patterns of samples were recorded in Fig. 2a. The peaks at $2 \theta=31.8^{\circ}, 34.5^{\circ}, 36.3^{\circ}, 56.6^{\circ}, 62.8^{\circ}$ were assigned to the characteristic peaks of (110), (006), (113), (300), (119), matching well with Zinc Hydroxide $\left(\mathrm{Zn}(\mathrm{OH})_{2}\right)(\mathrm{PDF} \# 48-1066)$ references. Additionally, the peaks at $2 \theta=62.7^{\circ}$ corresponded to the characteristic peaks of (440), matching well with Iron $\mathrm{Hydroxide}\left(\mathrm{Fe}(\mathrm{OH})_{3}\right)$ (PDF\#22-0346) references. The XRD peak of Ly @ FeZn was sharp, indicating that the prepared adsorbent maintains well- 
crystallinity. FT-IR spectra of Ly @ FeZn (Fig. 2b) demonstrated the presence of amino acids on LDH surface, as evidenced by the $\mathrm{N}-\mathrm{H}$ stretching vibration mode at $\sim 3417 \mathrm{~cm}^{-1}$ and $-\mathrm{COO}^{-}$stretching vibration mode at $\sim 1467 \mathrm{~cm}^{-1}$ [Koilraj et al. 2019, Koilraj and Sasaki. 2017]. The existence of the band at $\sim 1589 \mathrm{~cm}^{-1}$ corresponded to the $-\mathrm{C}-\mathrm{O}$ stretching vibration of the $-\mathrm{COO}^{-}$group of amino acid present on the LDH surface. Moreover, bands appeared at $\sim 2925 \mathrm{~cm}^{-1}$ relevant to the $-\mathrm{C}-\mathrm{H}$ stretching vibration mode. The Ly @ FeZn exhibited bands at $\sim 1382, \sim 982$ and $\sim 795 \mathrm{~cm}^{-1}$ related to the $\mathrm{N}-\mathrm{O}$ stretching vibration mode of $\mathrm{NO}_{3}{ }^{-}$. It showed that the interlayer anion of $\mathrm{LDH}$ synthesized by hydrothermal method is $\mathrm{NO}_{3}{ }^{-}$. The common peaks of $\sim 903 \mathrm{~cm}^{-1}$ were corresponded with the $\mathrm{M}-\mathrm{O}$ bending or $\mathrm{M}-\mathrm{OH}$ lattice vibrations (M: Fe or Zn) [Guo et al. 2020].

The morphology of Ly @ FeZn, Ly @ FeZn-CIP, Ly @ FeZn-NOR and Ly @ FeZn-OFL (Fig.3a-d) were visually presented by SEM images, as depicted in Fig.3a, Ly @ FeZn formed particles in the shape of elongated fragments adhere to rough surfaces and displayed large gaps with uneven distribution, which can provide plenty of adsorption sites for adsorbent [Zhu et al. 2020]. As revealed in Fig.3b and Fig.3c, the morphology of Ly @ FeZn after adsorption of CIP and NOR changed significantly. Ly @ FeZn-CIP and Ly @ FeZn-NOR had similarmorphology and formed an irregular sheet structure with smooth surface. This may be because CIP and NOR were inserted in the gaps of LDH and combined with amino acids and Ly @ FeZn adsorption sites on the surface, resulting in the structure of Ly @ FeZn-CIP and Ly @ FeZn-NOR were tightly layered. As shown in Fig.3d, the prismatic particles were clustered together, and the material were agglomerated. The reason for this may be that OFL directly wrapped Ly @ FeZn owing to the bulky structure of OFL. EDS elemental mapping images were illustrated in Fig. S1,the appearance of N element indicated that the Ly @ FeZn was fabricated successfully. Mapping images were showed in Fig. S2.

\subsection{Ly @ FeZn's different adsorption performance towards CIP, NOR and OFL}

\subsubsection{Effect of adsorbent dosage}

As shown in Fig. 4, the removal rate increased with Ly @ FeZn dosage, while the adsorption capacity gradually decreased. As the dosage of adsorbent increased, more active sites were available for adsorption due to the increase of vacant sites on the surface of Ly @ FeZn, resulting in the increase of antibiotics adsorption [Karthikeyan and Meenakshi. 2019]. The decrease of adsorption capacity may be attributed to the competition of adsorption sites at high dosages. Some available sites cannot be freely combined with antibiotics, thereby reducing the relative absorption of antibiotics on the Ly @ FeZn [Hu et al. 2020, Yao et al. 2017]. At the dosage of $0.05 \mathrm{~g}$, the removal rates of Ly @ FeZn for CIP and NOR were remarkable, which were as high as $98.48 \%$ and $95.05 \%$, respectively. However, the removal rate of Ly @ FeZn for OFL was relatively low (33.13\%) compared with the CIP and NOR. Related to the SEM images in Fig. 3d, the Ly @ FeZn-OFL was clustered together, CIP and NOR were directly intercalated between Ly @ FeZn voids or adsorbed on the surface. This might be the reason that the adsorption capacity of Ly @ FeZn for OFL was much smaller than that of CIP and NOR.

\subsubsection{Effect of solution $\mathrm{pH}$}

The influence of $\mathrm{pH}$ on antibiotics adsorption were illustrated in Fig.5. Physiochemical properties of relative antibiotics were given in Table 2. Noticeably, when pH value ranged from 3 to 10, the adsorption capacity of Ly @ FeZn for CIP exhibited minor variance.The maximum adsorption performance of Ly @ FeZn for CIP were achieved at pH of 7.This indicated the adsorption of Ly @ FeZn for CIPhad wide pH adaptability. The adsorption performance of Ly @ FeZn for NOR was like CIP at pH of 7. However, it was notably to notice that the adsorption capacityof Ly @ FeZn for NOR decreased dramatically at pH of 3 and 10, which was different with CIP. pK $\mathrm{a}_{\mathrm{a}}$ of CIP were 6.1 and 8.7 [Tang et al. 2020, Yu et al. 2016], while those of NORvalued of 6.22 and 8.51, respectively [Chahm et al. 2019]. CIP andNOR existed as a cationic, zwitterionic and anionic form in three regions divided by the two $\mathrm{pK}_{\mathrm{a}}$. CIP andNOR mainly existed in the form of amphoteric ions at pH of 7 (Table 2). Thus, CIP and NOR can be heavily adsorbed by Ly @ FeZn due to electrostatic interaction at pH of 7. On the contrary, it was difficult for adsorption due to electrostatic repulsion at PH of 3 and 10 [Cao et al. 2017, Tang et al. 2020, Wu et al. 2020, Yu et al. 2016]. Besides, the action of electrostatic repulsion was similar to LDHs at pH of 3 and 10. Thus, notability, lysine had a certain adsorption effect on CIP (the adsorption experiment of lysine on CIP was carried out), while the adsorption experiment of lysine on NOR indicated that lysine had noobvious effect for NOR removal at $\mathrm{pH} 3$ and 10. This led to a slight reduction of the CIP adsorption and dramatical decrease of NOR

Page 6/24 
adsorption. It should be noted that the adsorption capacity of CIP, NORand OFL were all the highest at pH of 7 . In this way, the further experiments were conducted at $\mathrm{pH}$ of 7.

Table 2 Physiochemical properties of CIP, NOR and OFL.

\begin{tabular}{|c|c|c|c|c|c|}
\hline Antibiotics & $\begin{array}{l}\text { Molecular } \\
\text { formula }\end{array}$ & $\begin{array}{l}\text { molecular } \\
\text { weight } \\
(\mathrm{g} / \mathrm{mol})\end{array}$ & $\mathrm{pK}_{\mathrm{a}}$ & $\begin{array}{l}\text { Chemical } \\
\text { structure }\end{array}$ & $\begin{array}{l}\text { Speciation } \\
\text { distribution }\end{array}$ \\
\hline CIP & $\mathrm{C}_{17} \mathrm{H}_{19} \mathrm{ClFN}_{3} \mathrm{O}_{3}$ & 385.82 & $\begin{array}{l}\text { 6.1/8.7 [Tang et al. 2020, } \\
\text { Yu et al. 2016] }\end{array}$ & & \\
\hline NOR & $\mathrm{C}_{16} \mathrm{H}_{18} \mathrm{FN}_{3} \mathrm{O}_{3}$ & 319.33 & $\begin{array}{l}\text { 6.22/8.51 [Chahm et al. } \\
\text { 2019] }\end{array}$ & & \\
\hline OFL & $\mathrm{C}_{18} \mathrm{H}_{20} \mathrm{FN}_{3} \mathrm{O}_{4}$ & 361.14 & $\begin{array}{l}6.08 / 8.25 \text { [Peng et al. } \\
\text { 2012] }\end{array}$ & & \\
\hline
\end{tabular}

\subsection{Adsorption kinetics, adsorption isotherms and thermodynamics}

\subsubsection{Adsorption kinetics}

The adsorption kinetic models of Ly @ FeZn for three antibiotics were illustrated in Fig. 6. The adsorption capacity of Ly @ FeZn for $\mathrm{CIP}$ and NOR exhibited a rapid increase in the first half hour and gradually reached equilibrium in $2 \mathrm{~h}$. The adsorption capacity of Ly @ FeZn for OFL increased with the contact time until $6 \mathrm{~h}$, then became constant, which indicated that the adsorption process was a long and complicated process [Fang et al. 2020]. Furthermore, the equilibrium adsorption capacity of Ly @ FeZn for CIP, NOR and OFL were 196.05, 190.27 and $61.00 \mathrm{mg} / \mathrm{g}$, respectively. The less adsorption capacity of OFL was attributed to the bulky structure of OFL, which posed steric hindrance for its interaction with the adsorbent. To study the adsorption kinetics, different kinetic models were applied to explain the kinetics of adsorption, and were illustrated as followings:

Pseudo-first-order kinetic model:

$$
q_{t}=q_{e}\left(1-e^{-k_{1} t}\right)
$$

4

Pseudo-second-order kinetic model:

$$
q_{t}=\frac{k_{2} q_{e}^{2} t}{1+k_{2} q_{e} t}
$$

5

The intra-particle diffusion model: 


$$
q_{t}=k_{i d} * t^{0.5}+C
$$

6

where $q_{e}(\mathrm{mg} / \mathrm{g})$ and $q_{t}(\mathrm{mg} / \mathrm{g})$ were denoted as equilibrium capacity and adsorption amount of antibiotics on Ly @ FeZn at corresponding time $(\mathrm{t}) ; k_{1}$ and $k_{2}$ represented the rate constants of the pseudo-first-order and pseudo-second-order models, respectively. The particle diffusion rate constant was $k_{i d}\left(\mathrm{mg} \cdot \mathrm{g}^{-1} \mathrm{~h}^{-1 / 2}\right)$, and $C$ represented the influence of boundary layer.

The calculated kinetic parameters for the three types of kinetic models were listed in Table 3, respectively. The CIP and NOR adsorption on Ly @ FeZn were well-described by the pseudo-first-order model, indicating that the suggested physisorption as the controlling mechanism [Zhu et al. 2020]. The pseudo-second-order model simulated well with OFL adsorption. This demonstrated that the adsorption rate was mainly dominated by the chemical interactions, and the adsorption capacity was proportional to the number of available active sites [Vibhu Sharma et al. 2017]. Furthermore, the intra-particle diffusion model was also applied to validate the potential rate control steps. For CIP, NOR and OFL, the first stage was the fastest owing to the diffusion of antibiotics to the outer surface of Ly @ FeZn through bulk solution, respectively.

Table 3

The parameters of kinetics models for CIP, NOR and OFL adsorption on Ly @ FeZn.

\begin{tabular}{|c|c|c|c|c|}
\hline \multirow[t]{2}{*}{ Type } & \multirow[t]{2}{*}{ Parameters } & \multicolumn{3}{|l|}{ Antibiotics } \\
\hline & & CIP & NOR & OFL \\
\hline \multirow[t]{3}{*}{ Pseudo-first-order kinetics } & $\mathrm{q}_{\mathrm{e}, \mathrm{cal}}(\mathrm{mg} / \mathrm{g})$ & 196.05 & 190.27 & 61.00 \\
\hline & $\mathrm{k}_{1}\left(\min ^{-1}\right)$ & $4.77 \times 10^{-2}$ & $2.24 \times 10^{-2}$ & $1.22 \times 10^{-2}$ \\
\hline & $\mathrm{R}^{2}$ & 0.999 & 0.996 & 0.992 \\
\hline \multirow[t]{3}{*}{ Pseudo-second-order kinetics } & $\mathrm{q}_{\mathrm{e}, \mathrm{cal}}(\mathrm{mg} / \mathrm{g})$ & 204.048 & 203.842 & 67.287 \\
\hline & $\mathrm{k}_{2}\left(\mathrm{~g} \cdot(\mathrm{mg} \cdot \min )^{-1}\right)$ & $3.29 \times 10^{-4}$ & $1.47 \times 10^{-4}$ & $2.48 \times 10^{-4}$ \\
\hline & $\mathrm{R}^{2}$ & 0.975 & 0.976 & 0.993 \\
\hline \multirow[t]{6}{*}{ Intra-particle diffusion model } & $\mathrm{k}_{1}\left(\mathrm{mg} \cdot\left(\mathrm{g} \cdot \mathrm{min}^{1 / 2}\right)^{-1}\right)$ & 35.177 & 18.740 & -8.488 \\
\hline & $\mathrm{R}^{2}$ & 0.999 & 0.974 & 0.994 \\
\hline & $\mathrm{k}_{2}\left(\mathrm{mg} \cdot\left(\mathrm{g} \cdot \mathrm{min}^{1 / 2}\right)^{-1}\right)$ & 0.367 & 1.135 & 1.660 \\
\hline & $\mathrm{R}^{2}$ & 1 & 1 & 1 \\
\hline & $k_{3}\left(m g \cdot\left(g \cdot \min ^{1 / 2}\right)^{-1}\right)$ & -0.047 & 0.272 & 0.112 \\
\hline & $\mathrm{R}^{2}$ & 1 & 1 & 1 \\
\hline
\end{tabular}

In addition, the adsorption capacity of CIP, NOR and OFL on Ly @ FeZn at 298 K were higher than those adsorbents reported in the literature (Table 4). According to the cited literature, the adsorption capacity of the prepared materials for CIP was in the range of 22.46-108.40 mg/g. Thus, the adsorption capacity of Ly @ FeZn for CIP was 1.8-8.7 times higher. Similarity, the adsorption capacity of the mentioned materials on NOR in the literature was in the range of 9.1-78.9 mg/g, and Ly @ FeZn for NOR was 2.420.8 times higher. In addition, the adsorption capacity of Ly @ FeZn for OFL was higher than the mentioned materials in the literature. 
Table 4

Comparison of adsorption capacity of various adsorbents for CIP, NOR and OFL.

\begin{tabular}{|c|c|c|c|c|c|c|}
\hline Antibiotics & Adsorbents & $\begin{array}{l}\mathrm{T} \\
(\mathrm{K})\end{array}$ & $\begin{array}{l}\text { Dosage } \\
\left(g \cdot L^{-1}\right)\end{array}$ & $\mathrm{pH}$ & $\begin{array}{l}\mathrm{q}_{\mathrm{e}} \\
\left(\mathrm{mg} \cdot \mathrm{g}^{-1}\right)\end{array}$ & Ref. \\
\hline \multirow[t]{4}{*}{ CIP } & diamine-functionalized MCM-41 & 298 & 1 & 7 & 108.40 & [Lu et al. 2020] \\
\hline & ZnO-SBA-15 (10\%) & 298 & 0.4 & 5 & 35 & [Sousa et al. 2018] \\
\hline & $\mathrm{Fe}_{3} \mathrm{O}_{4}$ nanoparticles & 298 & 2.5 & 7 & 22.46 & [Lin and Lee. 2020] \\
\hline & Ly @ FeZn & 298 & 1 & 7 & 196.05 & In this study \\
\hline \multirow[t]{4}{*}{ NOR } & $\begin{array}{l}\text { montmorillonite-biochar (MT-BC) } \\
\text { composite }\end{array}$ & 298 & 1.2 & 6.5 & 25.53 & [Zhang et al. 2018] \\
\hline & chemically activated termite & 298 & 1.25 & 8 & 78.9 & [Chahm et al. 2019] \\
\hline & modified Ni-Al LDH & 298 & 1 & 7 & 9.1 & $\begin{array}{l}\text { [Vibhu Sharma et al. } \\
\text { 2017] }\end{array}$ \\
\hline & Ly@ @eZn & 298 & 1 & 7 & 190.27 & In this study \\
\hline \multirow[t]{3}{*}{ OFL } & modified Ni-Al LDH & 298 & 1 & 7 & 8.5 & $\begin{array}{l}\text { [Vibhu Sharma et al. } \\
\text { 2017] }\end{array}$ \\
\hline & Chitosan/Biochar Composite & 298 & 0.2 & 6.5 & 3.2 & [Zhu et al. 2018] \\
\hline & Ly@ @ FeZn & 298 & 1 & 7 & 61.00 & In this study \\
\hline
\end{tabular}

\subsubsection{Adsorption isotherm}

The isotherm experiments were performed at temperature of $298 \mathrm{~K}$, and the results were displayed in Fig. 7. The adsorption capacity of CIP, NOR and OFL increased rapidly with initial concentration increasing until reached the maximum capacities. This phenomenon demonstrated that the concentration difference can promote the adsorption of CIP, NOR and OFL from the solution onto the Ly @ FeZn until the binding site of the adsorbent reached the adsorption saturation [Lin et al. 2019]. The adsorption isotherm was well simulated by Langmuir, Freundlich and Temkin models for comparison. The Langmuir model assumes an adsorption homogeneity, which is suitable for the monolayer adsorbate on the outer-sphere surface of the composites and without further adsorption. The Freundlich model assumes a heterogeneous adsorption that can be used to several types of binding sites on the surface of adsorbent [Wang et al. 2019]. The Temkin isotherm model is a chemical adsorption model between positive and negative charges based on strong electrostatic interaction [Zhu et al. 2020]. Mathematically, they were defined as:

$$
q=\frac{q_{m} K_{L} C_{e}}{1+K_{L} C_{e}}
$$

7

$$
q_{e}=K_{F} C_{e}^{1 / n}
$$

8

$$
q_{e}=K_{T} \ln \left(f C_{e}\right)
$$

9

where $q_{e}(\mathrm{mg} / \mathrm{g})$ and $q_{m}(\mathrm{mg} / \mathrm{g})$ were the equilibrium and maximum adsorption capacity, respectively; $C_{e}(\mathrm{mg} / \mathrm{L})$ was the equilibrium concentration; $K_{L}(\mathrm{~L} / \mathrm{mg})$ stood for the binding constant of adsorption heat; $n$ and $K_{F}$ were the Freundlich empirical constants relative to the adsorption intensity and the adsorption capacity, respectively; $K_{T}(\mathrm{~J} / \mathrm{mol})$ and $f(\mathrm{~L} / \mathrm{mg})$ were Temkin constant and Temkin binding constant, which reflected the heat of adsorption and maximum binding energy, respectively. 
The calculated isotherm parameters for three types of isotherm models were listed inTable 5. According to calculated correlation coefficients, the adsorption capacity of CIP and NOR on Ly @ FeZn well-described by the Langmuir model and the maximum adsorption capacities were 1218.96 and $71.12 \mathrm{mg} / \mathrm{g}$ for CIP and NOR, respectively. This indicated that CIP and NOR removal on Ly @ FeZn were governed by monolayer adsorption. Besides, the adsorption capacity of OFL on Ly @ FeZn well simulated with the Freundlich model and the maximum adsorption capacities was 120.39 mg/g. Experimental phenomena indicated that Ly @ FeZn had a flocculating effect for high-concentration NOR, but had no flocculation effect for low-concentration NOR, resulting in Ly @ FeZn had a better removal effect for high-concentration NOR, thereby the maximum removal capacity was different from the previous experimental results.

Table 5

The parameters of isotherm models for CIP, NOR and OFL adsorption on FeZn LDHs.

\begin{tabular}{|c|c|c|c|c|}
\hline \multirow[t]{2}{*}{ Type } & \multirow[t]{2}{*}{ Parameters } & \multicolumn{3}{|l|}{ Antibiotics } \\
\hline & & CIP & NOR & OFL \\
\hline \multirow[t]{3}{*}{ Langmuir } & $q_{m}\left(\mathrm{mg} \cdot \mathrm{g}^{-1}\right)$ & 1218.956 & 71.115 & 120.386 \\
\hline & $K_{L}\left(\mathrm{~L} \cdot \mathrm{mg}^{-1}\right)$ & 0.0350 & 0.0383 & 0.0059 \\
\hline & $\mathrm{R}^{2}$ & 0.956 & 0.989 & 0.986 \\
\hline \multirow[t]{3}{*}{ Freundlich } & $K_{F}\left(\mathrm{mg} \cdot \mathrm{g}^{-1}\right)\left(\mathrm{L} \cdot \mathrm{mg}^{-1}\right)^{1 / \mathrm{n}}$ & 50.035 & 4.587 & 1.566 \\
\hline & $1 / n$ & 0.784 & 0.638 & 0.723 \\
\hline & $\mathrm{R}^{2}$ & 0.945 & 0.976 & 0.987 \\
\hline \multirow[t]{3}{*}{ Temkin } & $K_{T}\left(\mathrm{~J} \cdot \mathrm{mol}^{-1}\right)$ & 200.445 & 13.166 & 16.849 \\
\hline & $f\left(\mathrm{~L} \cdot \mathrm{mg}^{-1}\right)$ & 0.536 & 0.490 & 0.135 \\
\hline & $\mathrm{R}^{2}$ & 0.976 & 0.988 & 0.945 \\
\hline
\end{tabular}

\subsubsection{Adsorption thermodynamics}

The thermodynamic isotherms of Ly @ FeZn for antibiotics under different temperatures ( $298 \mathrm{~K}, 308 \mathrm{~K}$ and $318 \mathrm{~K})$ were performed to further explore the adsorption mechanism. The parameters of Gibbs energy change $\left(\Delta \mathrm{G}^{0}\right)$, enthalpy change $\left(\Delta \mathrm{H}^{0}\right)$, and entropy change $\left(\Delta S^{0}\right)$ were calculated to illustrate the thermodynamic behavior under different temperatures. The positive or negative $\Delta \mathrm{G}^{0}$ values represented the non-spontaneous or spontaneous reactions. The $\Delta \mathrm{H}^{0}$ and $\Delta \mathrm{S}^{0}$ illustrated the endothermic or exothermal properties and chaotic change of the adsorption process, respectively. They were calculated from the equations [Yao et al. 2017, Yin et al. 2019]:

$$
\ln K_{0}=-\frac{\Delta H^{0}}{R} \times \frac{1}{T}+\frac{\Delta S^{0}}{R}
$$

$$
K_{0}=\frac{q_{e}}{C_{e}}
$$

$$
\Delta G^{0}=-R T \ln K_{0}
$$


where $T(\mathrm{~K})$ and $R\left(\mathrm{~kJ} / \mathrm{mol} \cdot \mathrm{K}^{-1}\right)$ were the Kelvin temperature and the ideal gas constant $\left(8.314 \mathrm{~J} / \mathrm{mol} \cdot \mathrm{K}^{-1}\right)$, respectively; $K_{0}$ represented the standard equilibrium constant.

The thermodynamic parameters from the temperature-dependent isotherms were tabulated in Table 6. The values of $\Delta H^{0}$ and $\Delta S^{0}$ were determined according to the slope and intercept of the linear plot of In $\mathrm{K}_{0}$ versus $1 / \mathrm{T}$, respectively (Fig. S3). The negative $\Delta H^{0}$ values indicated that the adsorption of CIP, NOR and OFL on Ly @ FeZn were exothermal process, which was consistent with the fact that the adsorption capacity increased at low temperature [Peng et al. 2015, Wang et al. 2015, Yao et al. 2017]. One possible explanation to the negative $\Delta H^{0}$ values was that the adsorption enthalpy was higher than the energy absorbed in the desolation process [Yao et al. 2017]. Values of $\Delta \mathrm{G}^{0}$ were negative, confirming that the adsorption of CIP and NOR on Ly @ FeZn were a spontaneous and favorable thermodynamically and more negative $\Delta G^{0}$ value at lower temperature indicated that the adsorption was more easier and the low temperature was more favorable for the binding of CIP and NOR to Ly @ FeZn [Arshadi et al. 2013, Zhao et al. 2014]. This consequence may be owing to the change of surface complexation constant at different temperatures [Yao et al. 2017]. The negative $\Delta S^{0}$ values may indicate the changes of solid structures, suggesting that the randomness of the whole adsorption systems at the solid-solution interface became lower after the adsorption processes [Wang et al. 2015].

Table 6

Thermodynamic parameters for CIP, NOR and OFL adsorption on FeZn LDHs.

\begin{tabular}{|c|c|c|c|c|c|}
\hline \multirow[t]{2}{*}{ Antibiotics } & \multirow[t]{2}{*}{$\Delta H^{P}\left(\mathrm{~kJ} \cdot \mathrm{mol}^{-1}\right)$} & \multirow[t]{2}{*}{$\Delta S^{0}\left(\mathrm{~J} \cdot(\mathrm{mol} \cdot \mathrm{K})^{-1}\right)$} & \multicolumn{3}{|c|}{$\Delta G^{0}\left(\mathrm{~kJ} \cdot \mathrm{mol}^{-1}\right)$} \\
\hline & & & $298.15 \mathrm{~K}$ & $308.15 \mathrm{~K}$ & $318.15 \mathrm{~K}$ \\
\hline CIP & -65.762 & -186.631 & -10.066 & -8.372 & -6.326 \\
\hline NOR & -34.556 & -90.669 & -7.564 & -6.529 & -5.756 \\
\hline OFL & -50.458 & -176.518 & 1.945 & 3.714 & 5.475 \\
\hline
\end{tabular}

\subsection{Ly @ FeZn's different removal mechanism on CIP, NOR and OFL 3.5.1 Flocculation/adsorption's synergistic removal mechanism on CIP and NOR}

To further investigate the interaction mechanism between three antibiotics and Ly @ FeZn composite, the high resolution XPS scans were measured. The chemical composition and oxidation state of elements of Ly @ FeZn, Ly @ FeZn-CIP and Ly @ FeZnNOR were examined by using XPS analyses and were shown in Fig. 8. The full XPS spectra of the samples shown in Fig. 8a demonstrated the existence of F species, which showed CIP, NOR and Ly @ FeZn interacted electrostatically.

Meanwhile, the high-resolution C 1s, $01 s, N$ 1s and Fe 2p spectra were also investigated (Fig. 8b-e). An apparent shift could be observed after CIP adsorption, which indicated the alteration of the bonding environments [Wen et al. 2014]. The $\mathrm{C}$ 1s signals of Ly @ FeZn and Ly @ FeZn-CIP can be divided into 3 peaks. The peaks at 284.8 eV, 285.95 eV and 288.75 eV of Ly @ FeZn attributed to $\mathrm{C}-\mathrm{C}, \mathrm{C}-\mathrm{O}$ and $\mathrm{C}=\mathrm{O}$, respectively [Zhang et al. 2019]. After CIP adsorption, $\mathrm{C}-\mathrm{O}$ shifted to a higher binding energy $(286.15 \mathrm{eV})$ and $\mathrm{C} \square \mathrm{O}$ shifted to a lower binding energy $(287.90 \mathrm{eV})$. In addition, the intensity of C 1s in Ly @ FeZn-CIP was much higher than that of C 1s in pure Ly @ FeZn (Fig. 8b), indicating that CIP was incorporated with Ly @ FeZn [Wen et al. 2014]. The 0 1s spectra of Ly @ FeZn displayed three major peaks with binding energies at $529.65 \mathrm{eV}, 531.07 \mathrm{eV}$ and $532.21 \mathrm{eV}$, corresponding to lattice oxygen, $\mathrm{M}$ -0 and hydroxy, respectively [Wang et al. 2019]. The M-O peak positions of Ly @ FeZn after CIP adsorption were shifted, suggesting that the metal ions (i.e., $\mathrm{Fe}^{3+}$ and $\mathrm{Zn}^{2+}$ ) were complexed with $-\mathrm{OH}$ groups of CIP on the surfaces of Ly @ FeZn [Sheng et al. 2016, Sheng et al. 2016, Wang et al. 2015, Wen et al. 2014]. The single peak of Ly @ FeZn at 399.67 eV, corresponding to CN. While signal of Ly @ FeZn-CIP was asymmetric, which can be divided into two peaks at $400.25 \mathrm{eV}$ and $398.82 \mathrm{eV}$, corresponding to $\mathrm{C}-\mathrm{N}$ and $-\mathrm{N} \square \mathrm{O}$ [Huang et al. 2019] The deconvoluted Fe $2 \mathrm{p}$ spectrum was fitted into six peaks. In the case of Fe $2 \mathrm{p}_{3 / 2}$ spectra, two peaks around $710.16 \mathrm{eV}, 711.48 \mathrm{eV}$ can be assigned to $\mathrm{Fe}^{2+}$ in octahedral sites and $\mathrm{Fe}^{3+}$ in octahedral sites. After the adsorption reaction, the relative intensity of the two peaks changed, which proved the conversion between $\mathrm{Fe}^{2+}$ and $\mathrm{Fe}^{3+}$ on the $\mathrm{Ly}$

Page $11 / 24$ 
@ FeZn surface [Hong et al. 2020, Huang et al. 2017]. Furthermore, it was likely that the chemical interaction between CIP and the surface hydroxyl caused the binding energy of Fe 2p to shift slightly to a more negative level [Lu et al. 2018].

After comparison, the XPS spectra of Ly @ FeZn-CIP and Ly @ FeZn-NOR were almost identical. Thereby, the analysis of Ly @ FeZn for NOR was similar to the of CIP. In addition, according to experimental phenomenon, Ly @ FeZn had a flocculating effect on both CIP and NOR. In summary, the adsorption mechanism of CIP and NOR on Ly @ FeZn were predominately electrostatic attraction, chemical bonding and flocculation. The adsorption mechanism was graphically illustrated in Fig. 9.

\subsubsection{Adsorption mechanism of Ly @ FeZn for OFL}

The chemical composition and oxidation state of elements of Ly @ FeZn-OFL was examined by using XPS analyses and was shown in Fig. 8. The full XPS spectra (Fig. 8a) demonstrated the existence of F species, which indicated OFL and Ly @ FeZn interacted electrostatically. Whereas compared with the XPS spectra of Ly @ FeZn, the XPS spectra of Ly @ FeZn-OFL had almost unchanged, suggesting OFL removal mainly was controlled by only electrostatic attraction. This quite different from that of CIP and NOR adsorption, which were dominated by electrostatic attraction and chemical bonding. This explained why the adsorption capacity of Ly @ FeZn for OFL was relatively low compared with CIP and NOR. Moreover, the adsorption mechanism of OFL was illustrated in Fig. 9.

\subsection{Recycle and reuse performance}

Furthermore, the recyclability and reusability of Ly @ FeZn was investigated for evaluating the adsorbent's economics. After achieved the adsorption equilibrium, the adsorbents were washed by deionized water for several times and dried overnight for further adsorption. As illustrated in Fig. S4, the adsorption of Ly @ FeZn for antibiotics could still efficient in fifth time adsorption (adsorption capacity: CIP was $127.86 \mathrm{mg} / \mathrm{g}$, NOR was $115.48 \mathrm{mg} / \mathrm{g}$ and OFL was $13.71 \mathrm{mg} / \mathrm{g}$ ). The significant regeneration for antibiotics indicated that Ly @ FeZn was an effective recyclable adsorbent for removing antibiotics from polluted water.

\section{Conclusions}

Ly @ FeZn with elongated fragments structure was synthesized by hydrothermal method. BBD model was conducted for the controllable fabrication of efficient Ly @ FeZn: temperature of $60^{\circ} \mathrm{C}$, Fe / Zn molar ratio of 0.5 and the lysine dosage of $5.8 \mathrm{mmol}$. The Ly @ FeZn may capture CIP and NOR molecule more efficiently than OFL owing to the smaller molecule length and less steric hindrance than OFL. The adsorption capacities of optimized Ly @ FeZn for CIP, NOR and OFL reached 193.83, 190.20 and 62.12 $\mathrm{mg} / \mathrm{g}$, respectively. Moreover, the adsorption process of Ly @ FeZn for CIP and NOR exhibited similar adsorption mechanism: predominately driven by the combined mechanism of electrostatic attraction, chemical bonding and flocculation. On the other hand, the adsorption behavior of OFL was controlled by electrostatic attraction. In addition, the regeneration performance of Ly @ FeZn was also considerable.

\section{Declarations}

Author contribution Yuying Hu conceptualization, methodology, writing, review \& editing. Susu Liu investigation, methodology, writing - original draft, visualization. Min Qiu investigation, methodology. Xiaohuan Zheng investigation, methodology. Xiaoming Peng conceptualization, writing - review \& editing, supervision. Hongling Dai validation, formal analysis, visualization. Fengping Hu resources, writing - review \& editing, supervision. Li Xu resources, writing - review \& editing. Gaoping Xu resources, writing - review \& editing.

Funding This work was supported by the Natural Science Foundation of Jiangxi Province (NO. 20212ACB204003, NO. 20192BCD40013), National Natural Science Foundation of China (NO. 51908213, NO. 51908214, NO. 61872141).

Availability of data and materials Extra data are available from the author (huyuying@foxmail.com) on reasonable request.

Ethics statement No animal studies are presented in this manuscript. No human studies are presented in this manuscript. No potentially identifiable human images or data are presented in this work.

Consent for participation Not applicable. 
Consent for publication Not applicable.

Competing interests The authors declare no competing interests.

\section{References}

1. Alemtsehay TR, Zhang D, Xin L (2018) Rapid and Selective Uranium Adsorption by Glycine functionalized Europium Hydroxide. Colloids and Surfaces A Physicochemical and Engineering Aspects 556:299-308. http://dx.doi.org/10.1016/j.colsurfa.2018.08.039

2. Arshadi M, Salimi Vahid F, Salvacion JWL, Soleymanzadeh M (2013) A practical organometallic decorated nano-size $\mathrm{SiO}_{2}-$ $\mathrm{Al}_{2} \mathrm{O}_{3}$ mixed-oxides for methyl orange removal from aqueous solution. Appl Surf Sci 280:726-736. http://dx.doi.org/10.1016/j.apsusc.2013.05.052

3. Asiabi H, Yamini Y, Shamsayei M (2017) Highly selective and efficient removal of arsenic(V), chromium(VI) and selenium(VI) oxyanions by layered double hydroxide intercalated with zwitterionic glycine. J Hazard Mater 339:239-247. http://dx.doi.org/10.1021/acs.chemmater.7b00618

4. Azhar MR, Abid HR, Periasamy V, Sun H, Tade MO, Wang S (2017) Adsorptive removal of antibiotic sulfonamide by UiO-66 and ZIF-67 for wastewater treatment. J Colloid Interface Sci 500:88-95. http://dx.doi.org/10.1016/j.jcis.2017.04.001

5. Cao E, Duan W, Wang A, Zheng Y (2017) Oriented growth of poly(m-phenylenediamine) on Calotropis gigantea fiber for rapid adsorption of ciprofloxacin. Chemosphere 171:223-230. http://dx.doi.org/10.1016/j.chemosphere.2016.12.087

6. Carabineiro SAC, Thavorn-amornsri T, Pereira MFR, Serp P, Figueiredo JL (2012) Comparison between activated carbon, carbon xerogel and carbon nanotubes for the adsorption of the antibiotic ciprofloxacin. Catal Today 186:29-34. http://dx.doi.org/10.1016/j.cattod.2011.08.020

7. Chahm T, de Souza LF, Dos Santos NR, da Silva BA, Rodrigues CA (2019) Use of chemically activated termite feces a low-cost adsorbent for the adsorption of norfloxacin from aqueous solution. Water Sci Technol 79:291-301. http://dx.doi.org/10.2166/wst.2019.052

8. Chen W, Li X, Pan Z, Bao Y, Ma S, Li L (2015) Efficient adsorption of Norfloxacin by Fe-MCM-41 molecular sieves: Kinetic, isotherm and thermodynamic studies. Chem Eng J 281:397-403. http://dx.doi.org/10.1016/j.cej.2015.06.121

9. Chen WQ, Li L, Li L, Qiu WH, Tang L, Xu L, Xu K, Wu MH (2019) MoS 2 /ZIF-8 Hybrid Materials for Environmental Catalysis: Solar-Driven Antibiotic-Degradation Engineering. Engineering http://dx.doi.org/10.1016/j.eng.2019.02.003

10. Crespo-Alonso M, Nurchi VM, Biesuz R, Alberti G, Spano N, Pilo MI, Sanna G (2013) Biomass against emerging pollution in wastewater: Ability of cork for the removal of ofloxacin from aqueous solutions at different pH. J Environ Chem Eng 1:11991204. http://dx.doi.org/10.1016/j.jece.2013.09.010

11. Fang X, Wu S, Wu Y, Yang W, Li Y, He J, Hong P, Nie M, Xie C, Wu Z, Zhang K, Kong L, Liu J (2020) High-efficiency adsorption of norfloxacin using octahedral UIO-66- $\mathrm{NH}_{2}$ nanomaterials: Dynamics, thermodynamics, and mechanisms. Appl Surf Sci 518:146226. http://dx.doi.org/10.1016/j.apsusc.2020.146226

12. Guo Y, Gong Z, Li C, Gao B, Li P, Wang X, Zhang B, Li X (2020) Efficient removal of uranium (VI) by 3D hierarchical Mg/Fe-LDH supported nanoscale hydroxyapatite: A synthetic experimental and mechanism studies. Chem Eng J 392. http://dx.doi.org/10.1016/j.cej.2019.123682

13. Hong J, Zhu Z, Lu H, Qiu Y (2014) Synthesis and arsenic adsorption performances of ferric-based layered double hydroxide with @a-alanine intercalation. Chemical Engineering Journal Lausanne. http://dx.doi.org/10.1016/j.cej.2014.05.019

14. Hong Y, Zhou H, Xiong Z, Liu Y, Yao G, Lai B (2020) Heterogeneous activation of peroxymonosulfate by CoMgFe-LDO for degradation of carbamazepine: Efficiency, mechanism and degradation pathways. Chem Eng J 391:123604. http://dx.doi.org/10.1016/j.cej.2019.123604

15. Hu X, Hu X, Peng Q, Zhou L, Ning Z (2019) Mechanisms underlying the photocatalytic degradation pathway of ciprofloxacin with heterogeneous $\mathrm{TiO}_{2}$. Chem Eng J 380:122366. http://dx.doi.org/10.1016/j.cej.2019.122366

16. Hu Y, Pan C, Zheng X, Liu S, Hu F, Xu L, Xu G, Peng X (2020) Removal of Ciprofloxacin with Aluminum-Pillared Kaolin Sodium Alginate Beads (CA-Al-KABs): Kinetics, Isotherms, and BBD Model. Water 12:905. http://dx.doi.org/10.3390/w12030905 
17. Huang G-X, Wang C-Y, Yang C-W, Guo P-C, Yu H-Q (2017) Degradation of Bisphenol A by Peroxymonosulfate Catalytically Activated with $\mathrm{Mn}_{1.8} \mathrm{Fe}_{1.2} \mathrm{O}_{4}$ Nanospheres: Synergism between $\mathrm{Mn}$ and Fe. Environ Sci Technol 51:12611-12618. http://dx.doi.org/10.1021/acs.est.7b03007

18. Huang Z, Wang T, Shen M, Huang Z, Chong Y, Cui L (2019) Coagulation treatment of swine wastewater by the method of insitu forming layered double hydroxides and sludge recycling for preparation of biochar composite catalyst. Chem Eng $\mathrm{J}$ 369:784-792. http://dx.doi.org/10.1016/j.cej.2019.03.136

19. Jiang W-T, Wang C-J, Li Z (2013) Intercalation of ciprofloxacin accompanied by dehydration in rectorite. Appl Clay Sci 74:7480. http://dx.doi.org/10.1016/j.clay.2012.07.009

20. Jing S, Wang X, Tan Y (2018) Preparation of lysine-decorated polymer-brush-grafted magnetic nanocomposite for the efficient and selective adsorption of organic dye. Appl Surf Sci 441:654-662. http://dx.doi.org/10.1016/j.apsusc.2018.01.259

21. Kang J, Levitskaia TG, Park S, Kim J, Varga T, Um W (2020) Nanostructured MgFe and CoCr layered double hydroxides for removal and sequestration of iodine anions. Chem Eng J 380:122408. http://dx.doi.org/10.1016/j.cej.2019.122408

22. Karthikeyan P, Meenakshi S (2019) Synthesis and characterization of Zn-Al LDHs/activated carbon composite and its adsorption properties for phosphate and nitrate ions in aqueous medium. J Mol Liq 296:111766.

http://dx.doi.org/10.1016/j.molliq.2019.111766

23. Koilraj P, Kalusulingam R, Sasaki K (2019) Arginine and lysine-functionalized layered double hydroxides as efficient sorbents for radioactive $\mathrm{Co}^{2+}$ removal by chelate-facilitated immobilization. Chem Eng J 374:359-369.

http://dx.doi.org/10.1016/j.cej.2019.05.166

24. Koilraj P, Sasaki K (2017) Eco-Friendly Alkali-Free Arginine-Assisted Hydrothermal Synthesis of Different Layered Double Hydroxides and Their Chromate Adsorption/Reduction Efficiency. ChemistrySelect 2:10459-10469.

http://dx.doi.org/10.1002/slct.201702134

25. Koyuncu I, Arikan OA, Wiesner MR, Rice C (2008) Removal of hormones and antibiotics by nanofiltration membranes. J Membr Sci 309:94-101. http://dx.doi.org/10.1016/j.memsci.2007.10.010

26. Lin C-C, Lee C-Y (2020) Adsorption of ciprofloxacin in water using Fe304 nanoparticles formed at low temperature and high reactant concentrations in a rotating packed bed with co-precipitation. Mater Chem Phys 240:122049. http://dx.doi.org/10.1016/j.matchemphys.2019.122049

27. Lin G, Zhu L, Duan T, Zhang L, Liu B, Lei J (2019) Efficient capture of iodine by a polysulfide-inserted inorganic NiTi-layered double hydroxides. Chem Eng J 378:122181. http://dx.doi.org/10.1016/j.cej.2019.122181

28. Lu D, Xu S, Qiu W, Sun Y, Liu X, Yang J, Ma J (2020) Adsorption and desorption behaviors of antibiotic ciprofloxacin on functionalized spherical MCM-41 for water treatment. J Cleaner Prod 264:121644. http://dx.doi.org/10.1016/j.jclepro.2020.121644

29. Lu H, Lu T, Zhang H, Qiu Y, Yin D, Zhu Z (2018) Enhanced adsorption performance of aspartic acid intercalated Mg-Zn-Fe-LDH materials for arsenite. Dalton Trans 47:4994-5004. http://dx.doi.org/10.1039/C8DT00199E

30. Mehrjouei M, Mueller S, Moeller D (2014) Treatment of pyrolysis wastewater using heterogeneous advanced oxidation processes. Environ Prog Sustainable Energy 33:178-183. http://dx.doi.org/10.1002/ep.11778

31. Peng C, Dai J, Yu J, Yin J (2015) Calcined Mg-Fe layered double hydroxide as an absorber for the removal of methyl orange. AlP Adv 5:057138. http://dx.doi.org/10.1063/1.4921455

32. Peng H, Pan B, Wu M, Liu R, Zhang D, Wu D, Xing B (2012) Adsorption of ofloxacin on carbon nanotubes: solubility, pH and cosolvent effects. J Hazard Mater 211-212:342-348. http://dx.doi.org/10.1016/j.jhazmat.2011.12.063

33. Sen K, Datta JK, Mondal NK (2019) Glyphosate adsorption by Eucalyptus camaldulensis bark-mediated char and optimization through response surface modeling. Appl Water Sci 9:162. http://dx.doi.org/10.1007/s13201-019-1036-3

34. Sheng G, Hu J, Li H, Li J, Huang Y (2016) Enhanced sequestration of $\mathrm{Cr}(\mathrm{VI})$ by nanoscale zero-valent iron supported on layered double hydroxide by batch and XAFS study. Chemosphere 148:227-232.

http://dx.doi.org/10.1016/j.chemosphere.2016.01.035

35. Sheng G, Tang Y, Linghu W, Wang L, Li J, Li H, Wang X, Huang Y (2016) Enhanced immobilization of $\mathrm{ReO}_{4}-$ by nanoscale zerovalent iron supported on layered double hydroxide via an advanced XAFS approach: Implications for $\mathrm{TcO}_{4}{ }^{-}$sequestration. 
Appl Catal, B 192:268-276. http://dx.doi.org/10.1016/j.apcatb.2016.04.001

36. Singh D, Singh SK, Atar N, Krishna V (2016) Amino acid functionalized magnetic nanoparticles for removal of Ni(II) from aqueous solution. J Taiwan Inst Chem Eng 1-13. http://dx.doi.org/10.1016/j.jtice.2016.06.017

37. Singh KP, Gupta S, Singh AK, Sinha S (2011) Optimizing adsorption of crystal violet dye from water by magnetic nanocomposite using response surface modeling approach. J Hazard Mater 186:1462-1473. http://dx.doi.org/10.1016/j.jhazmat.2010.12.032

38. Sousa WRDN, Oliveira AR, Cruz Filho JF, Dantas TCM, Santos AGD, Caldeira VPS, Luz GE (2018) Ciprofloxacin Adsorption on ZnO Supported on SBA-15. Water Air Soil Pollut 229:125. http://dx.doi.org/10.1007/s11270-018-3778-1

39. Sun Y, Yang Y, Yang M, Yu F, Ma J (2019) Response surface methodological evaluation and optimization for adsorption removal of ciprofloxacin onto graphene hydrogel. J Mol Liq 284:124-130. http://dx.doi.org/10.1016/j.molliq.2019.03.118

40. Tang Y, Chen Q, Li W, Xie X, Zhang W, Zhang X, Chai H, Huang Y (2020) Engineering magnetic N-doped porous carbon with super-high ciprofloxacin adsorption capacity and wide $\mathrm{pH}$ adaptability. J Hazard Mater 388:122059. http://dx.doi.org/10.1016/j.jhazmat.2020.122059

41. Tran HN, Lin C-C, Chao H-P (2018) Amino acids-intercalated Mg/Al layered double hydroxides as dual-electronic adsorbent for effective removal of cationic and oxyanionic metal ions. Sep Purif Technol 192:36-45.

http://dx.doi.org/10.1016/j.seppur.2017.09.060

42. Vibhu Sharma R, Vinoth Kumar K, Pakshirajan, Pugazhenthi G (2017) Integrated adsorption-membrane filtration process for antibiotic removal from aqueous solution. Powder Technol 321:259-269. http://dx.doi.org/10.1016/j.powtec.2017.08.040

43. Wang C-J, Li Z, Jiang W-T (2011) Adsorption of ciprofloxacin on 2:1 dioctahedral clay minerals. Appl Clay Sci 53:723-728. http://dx.doi.org/10.1016/j.clay.2011.06.014

44. Wang J, Kang D, Yu X, Ge M, Chen Y (2015) Synthesis and characterization of Mg-Fe-La trimetal composite as an adsorbent for fluoride removal. Chem Eng J 264:506-513. http://dx.doi.org/10.1016/j.cej.2014.11.130

45. Wang J, Zhu M, Chen Z, Chen Y, Hayat T, Alsaedi A, Wang X (2019) Polyacrylamide modified molybdenum disulfide composites for efficient removal of graphene oxide from aqueous solutions. Chem Eng J 361:651-659.

http://dx.doi.org/10.1016/j.cej.2018.12.123

46. Wang Y, Jiang C, Le Y, Cheng B, Yu J (2019) Hierarchical honeycomb-like Pt/NiFe-LDH/rGO nanocomposite with excellent formaldehyde decomposition activity. Chem Eng J 365:378-388. http://dx.doi.org/10.1016/j.cej.2019.01.187

47. Wen T, Wu X, Liu M, Xing Z, Wang X, Xu AW (2014) Efficient capture of strontium from aqueous solutions using graphene oxide-hydroxyapatite nanocomposites. Dalton Trans 43:7464-7472. http://dx.doi.org/10.1039/c3dt53591f

48. Wu Y, Zheng H, Li H, Sun Y, Zhao C, Zhao R, Zhang C (2020) Magnetic nickel cobalt sulfide/sodium dodecyl benzene sulfonate with excellent ciprofloxacin adsorption capacity and wide pH adaptability. Chem Eng J 127208. http://dx.doi.org/10.1016/j.cej.2020.127208

49. Yan B, Niu CH, Wang J (2017) Kinetics, electron-donor-acceptor interactions, and site energy distribution analyses of norfloxacin adsorption on pretreated barley straw. Chem Eng J 330:1211-1221. http://dx.doi.org/10.1016/j.cej.2017.08.056

50. Yang D, Wang X, Song G, Zhao G, Chen Z, Yu S, Gu P, Wang H, Wang X (2017) One-pot synthesis of arginine modified hydroxyapatite carbon microsphere composites for efficient removal of $\mathrm{U}(\mathrm{VI})$ from aqueous solutions. Sci Bull 1609-1618. http://dx.doi.org/10.1016/j.scib.2017.10.018

51. Yang J, Zhang J, Zhang J, Zhang J, Yang Y, Zang L (2021) Roles of calcium-containing alkali materials on dark fermentation and anaerobic digestion: A systematic review. Int J Hydrog Energy 46:38645-38662.

http://dx.doi.org/10.1016/j.ijhydene.2021.09.129

52. Yang W, Lu Y, Zheng F, Xue X, Li N, Liu D (2012) Adsorption behavior and mechanisms of norfloxacin onto porous resins and carbon nanotube. Chem Eng J 179:112-118. http://dx.doi.org/10.1016/j.cej.2011.10.068

53. Yao W, Yu S, Wang J, Zou Y, Lu S, Ai Y, Alharbi NS, Alsaedi A, Hayat T, Wang X (2017) Enhanced removal of methyl orange on calcined glycerol-modified nanocrystallined Mg/Al layered double hydroxides. Chem Eng J 307:476-486. http://dx.doi.org/10.1016/j.cej.2016.08.117

54. Yin L, Hu Y, Ma R, Wen T, Wang X, Hu B, Yu Z, Hayat T, Alsaedi A, Wang X (2019) Smart construction of mesoporous carbon templated hierarchical $\mathrm{Mg}$-Al and $\mathrm{Ni}-\mathrm{Al}$ layered double hydroxides for remarkably enhanced $\mathrm{U}(\mathrm{VI})$ management. Chem Eng $\mathrm{J}$

Page 15/24 
359:1550-1562. http://dx.doi.org/10.1016/j.cej.2018.11.017

55. Yu F, Sun S, Han S, Zheng J, Ma J (2016) Adsorption removal of ciprofloxacin by multi-walled carbon nanotubes with different oxygen contents from aqueous solutions. Chem Eng J 285:588-595. http://dx.doi.org/10.1016/j.cej.2015.10.039

56. Zhang C, Shan C, Jin Y, Tong M (2014) Enhanced removal of trace arsenate by magnetic nanoparticles modified with arginine and lysine. Chem Eng J 254:340-348. http://dx.doi.org/10.1016/j.cej.2014.05.133

57. Zhang J, Lu M, Wan J, Sun Y, Lan H, Deng X (2018) Effects of pH, dissolved humic acid and $\mathrm{Cu}^{2+}$ on the adsorption of norfloxacin on montmorillonite-biochar composite derived from wheat straw. Biochem Eng J 130:104-112.

http://dx.doi.org/10.1016/j.bej.2017.11.018

58. Zhang P, Ouyang S, Li P, Huang Y, Frost RL (2019) Enhanced removal of ionic dyes by hierarchical organic three-dimensional layered double hydroxide prepared via soft-template synthesis with mechanism study. Chem Eng J 360:1137-1149. http://dx.doi.org/10.1016/j.cej.2018.10.179

59. Zhao Y, Shao Z, Chen C, Hu J, Chen H (2014) Effect of environmental conditions on the adsorption behavior of Sr(II) by Narectorite. Appl Clay Sci 87:1-6. http://dx.doi.org/10.1016/j.clay.2013.11.021

60. Zhu C, Lang Y, Liu B, Zhao H (2018) Ofloxacin Adsorption on Chitosan/Biochar Composite: Kinetics, Isotherms, and Effects of Solution Chemistry. Polycyclic Aromat Compd 39:287-297. http://dx.doi.org/10.1080/10406638.2018.1464039

61. Zhu S, Asim Khan M, Wang F, Bano Z, Xia M (2020) Rapid removal of toxic metals $\mathrm{Cu}^{2+}$ and $\mathrm{Pb}^{2+}$ by amino trimethylene phosphonic acid intercalated layered double hydroxide: A combined experimental and DFT study. Chem Eng J 392:123711. http://dx.doi.org/10.1016/j.cej.2019.123711

62. Zhu Z, Ouyang S, Li P, Shan L, Ma R, Zhang P (2020) Persistent organic pollutants removal via hierarchical flower-like layered double hydroxide: Adsorption behaviors and mechanism investigation. Appl Clay Sci 188:105500.

http://dx.doi.org/10.1016/j.clay.2020.105500

\section{Figures}


(a)

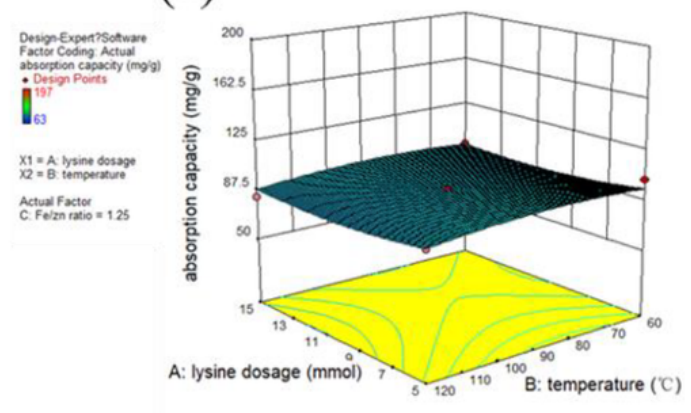

(b)

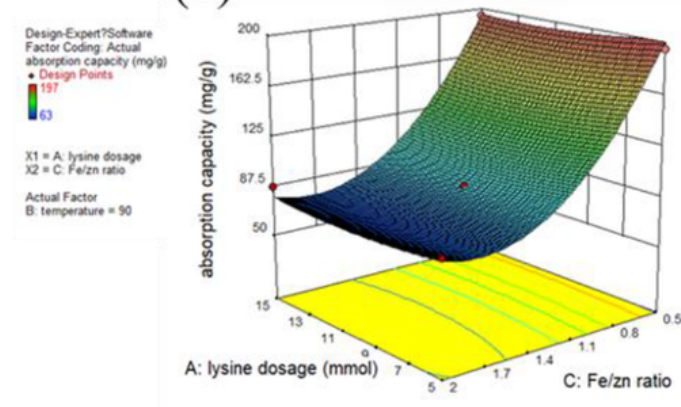

(c)
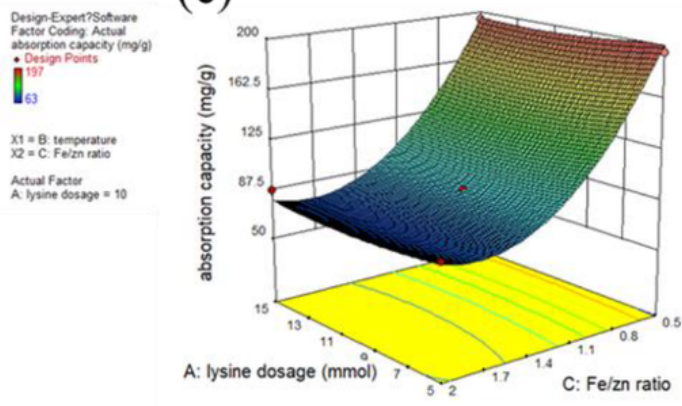

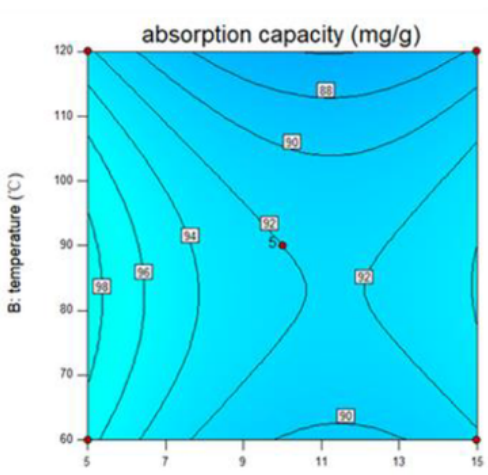

A: lysine dosage (mmol)

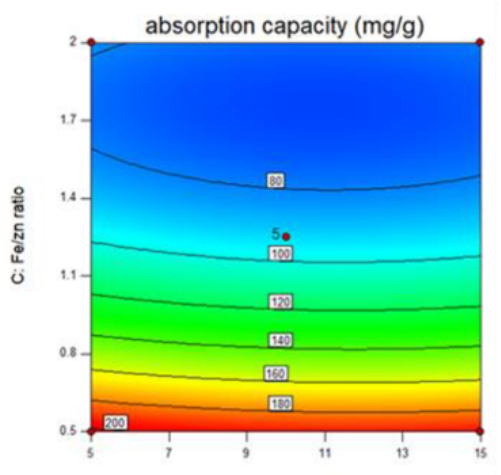

A: lysine dosage (mmol)

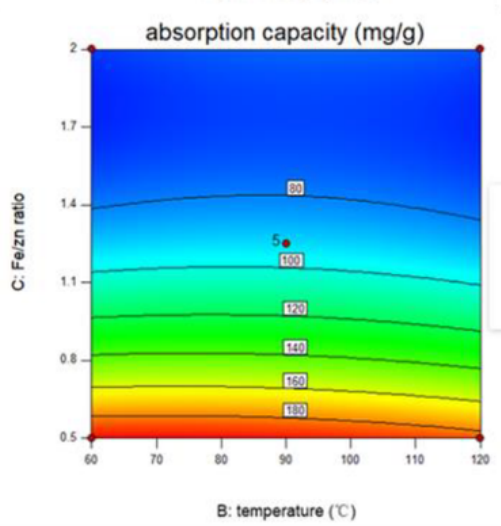

\section{Figure 1}

3D surface plots of adsorption capacity of Ly @ FeZn for CIP. 
(a)

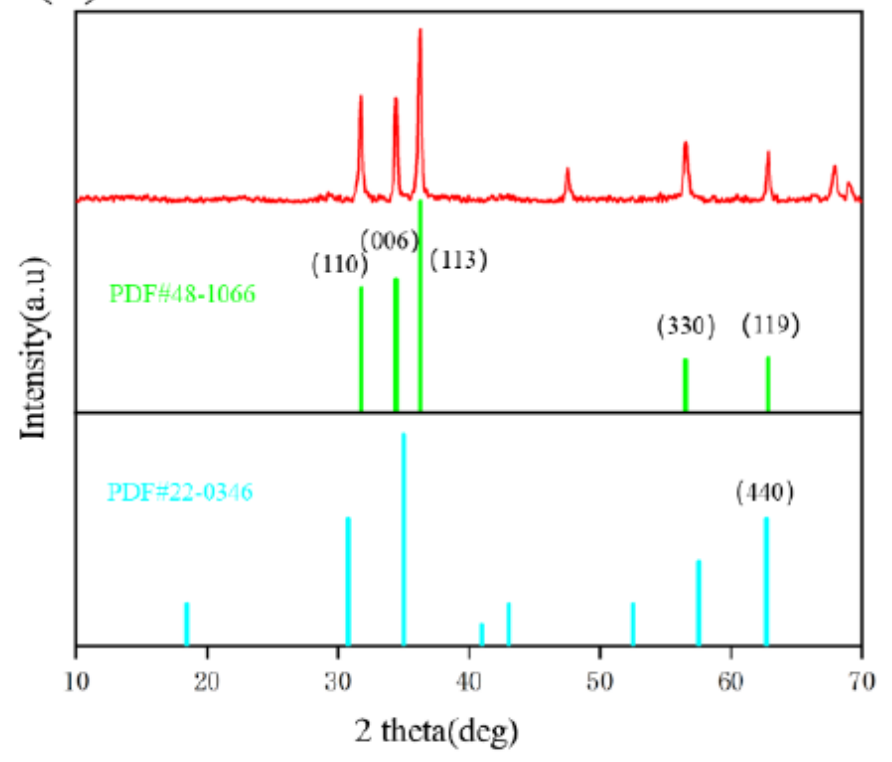

(b)

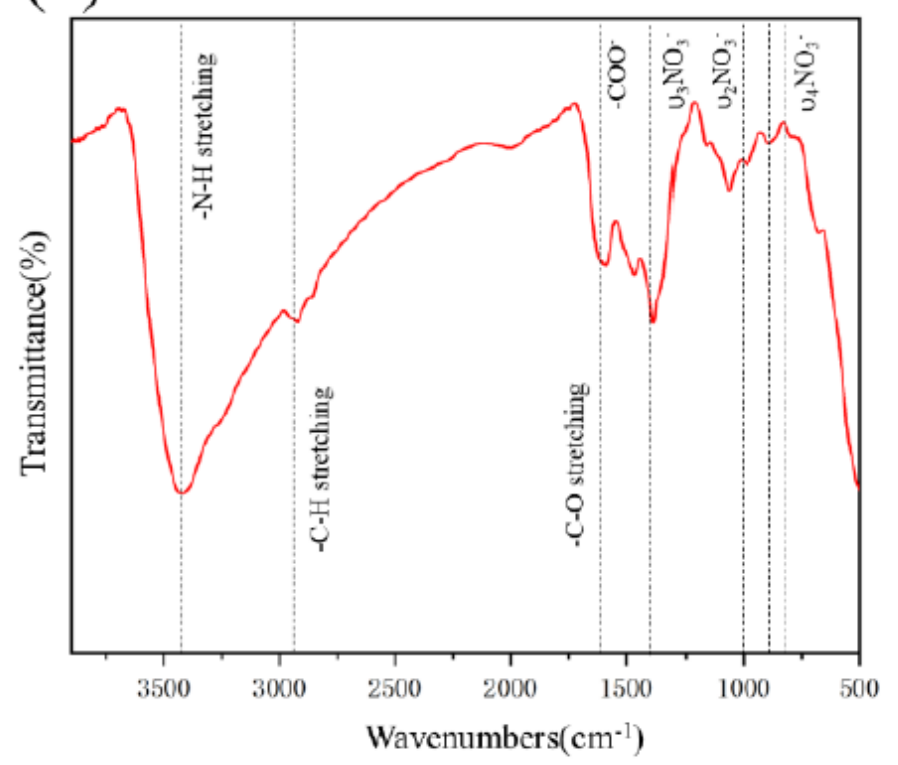

Figure 2

XRD pattern (a) and FT-IR spectra (b) of Ly @ FeZn. 

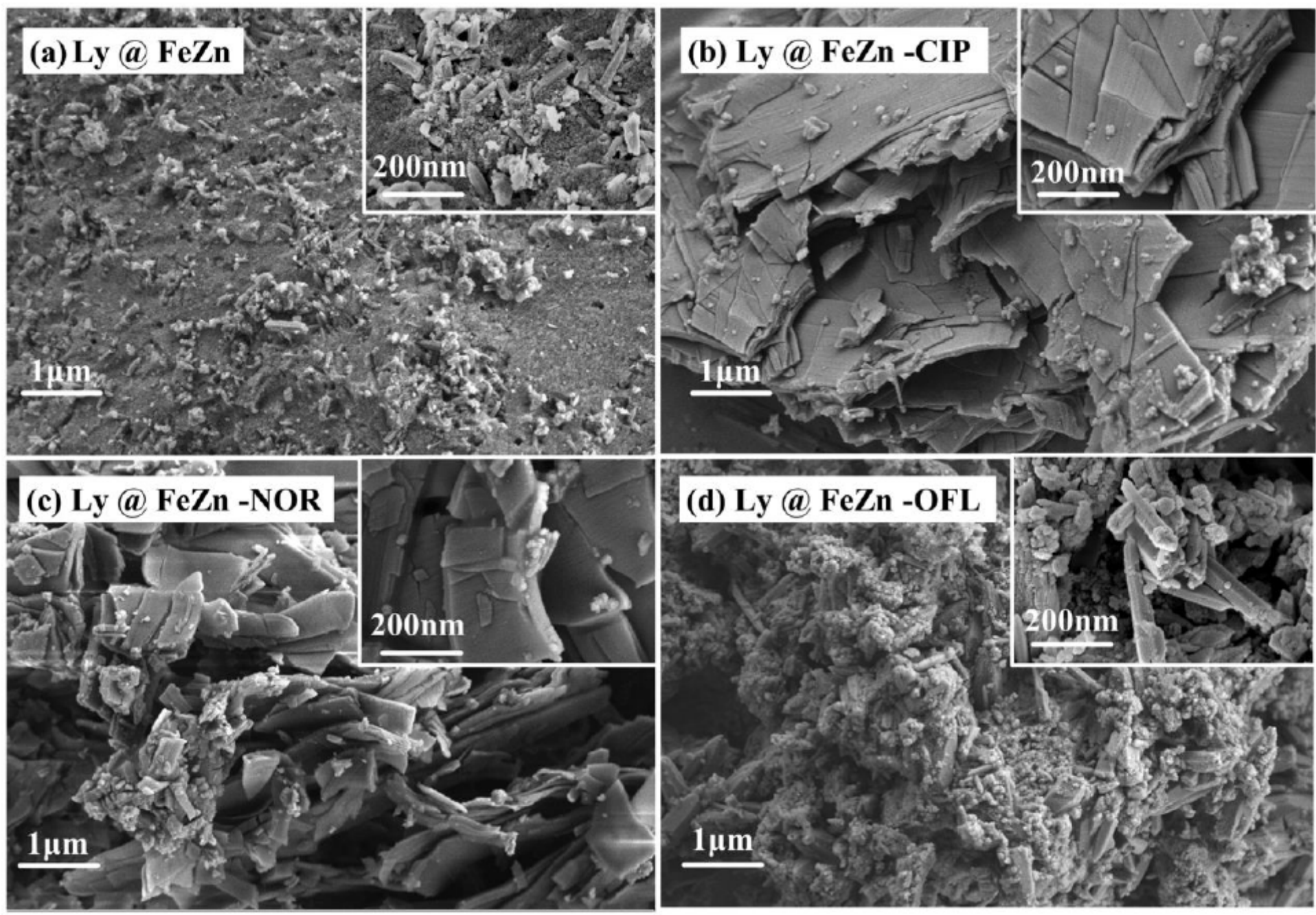

Figure 3

SEM images of Ly @ FeZn (a), Ly @ FeZn-CIP (b), Ly @ FeZn-NOR (c) and Ly @ FeZn-OFL (d).

(a)

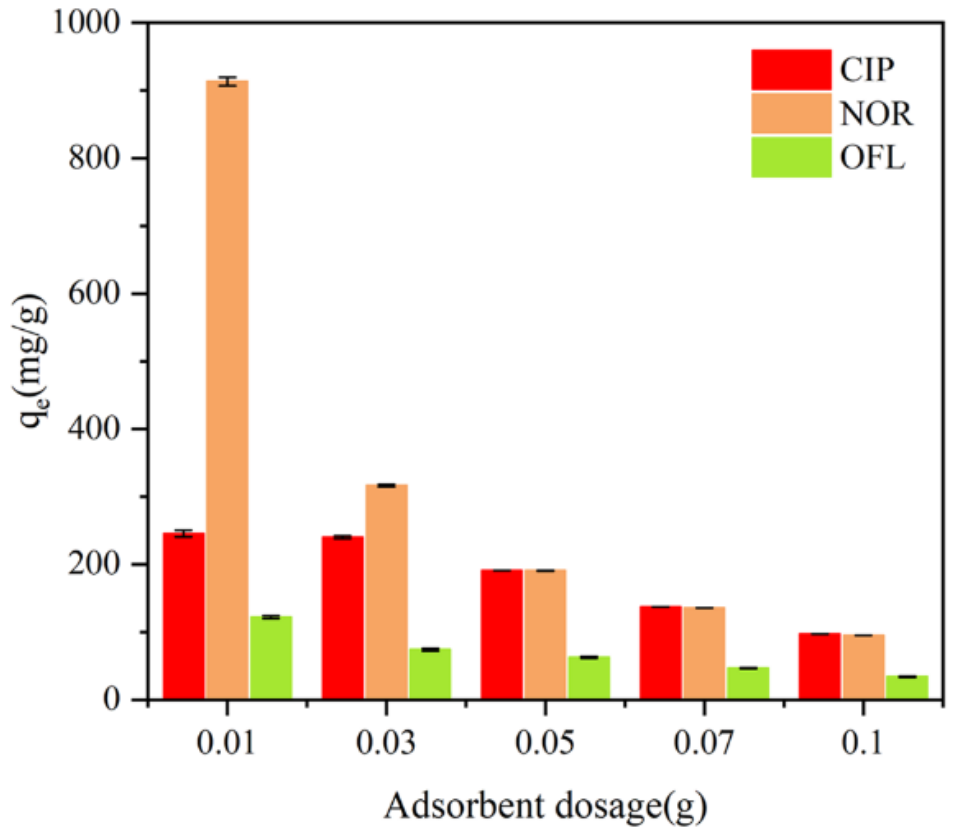

(b)

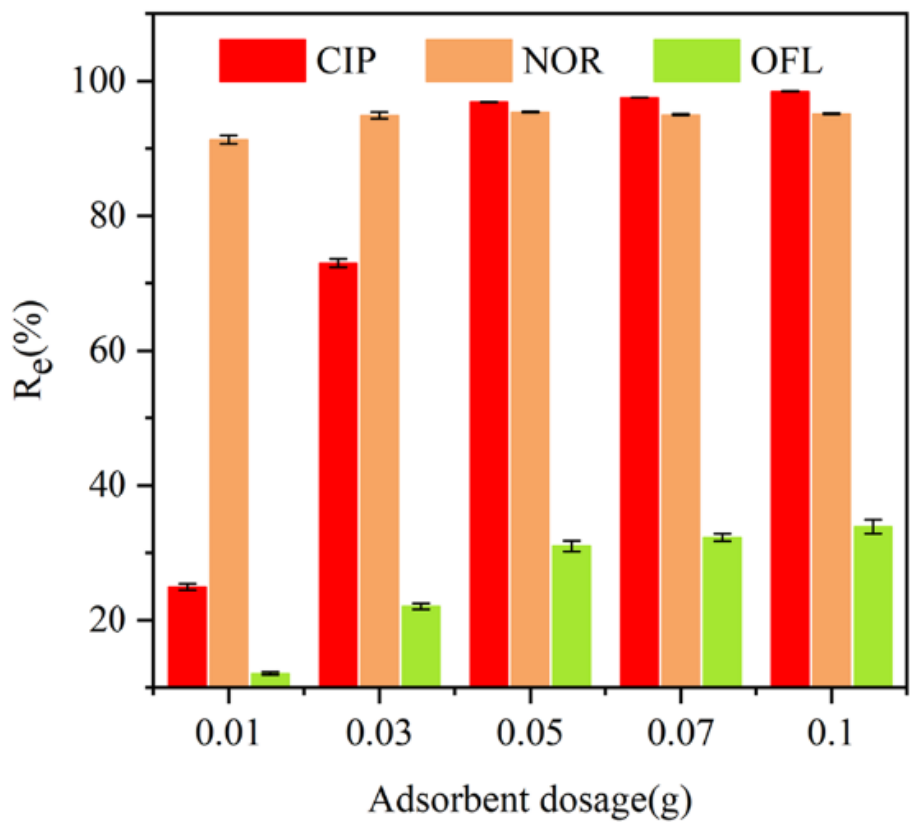


Figure 4

Effect of adsorbent dosage: adsorption capacity (a); removal rate (b).

(a)

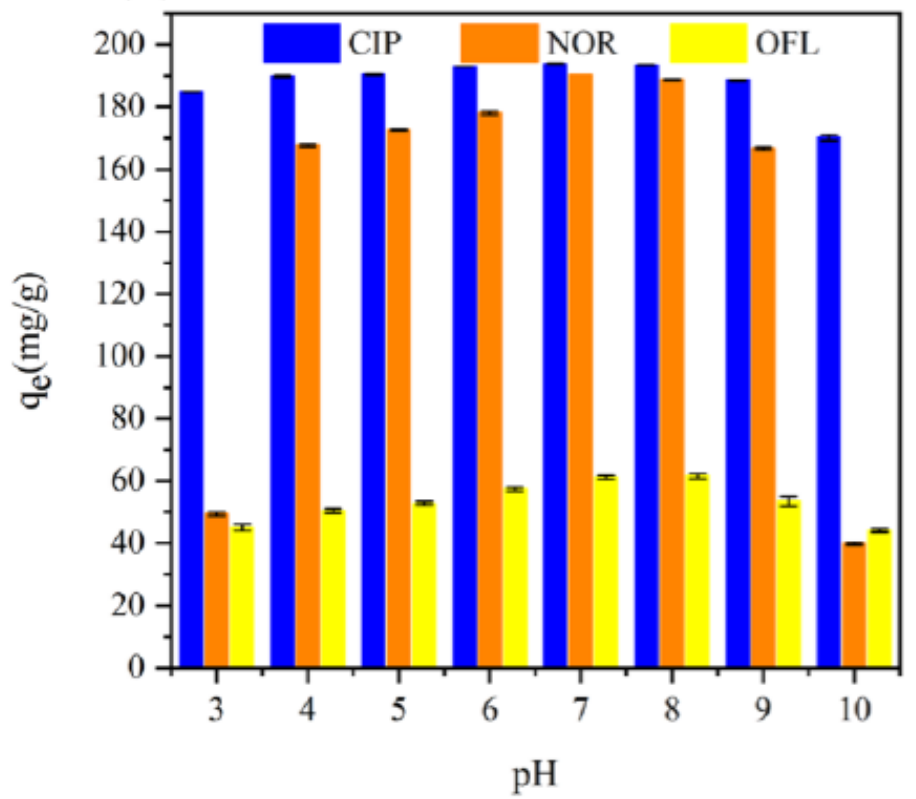

(b)

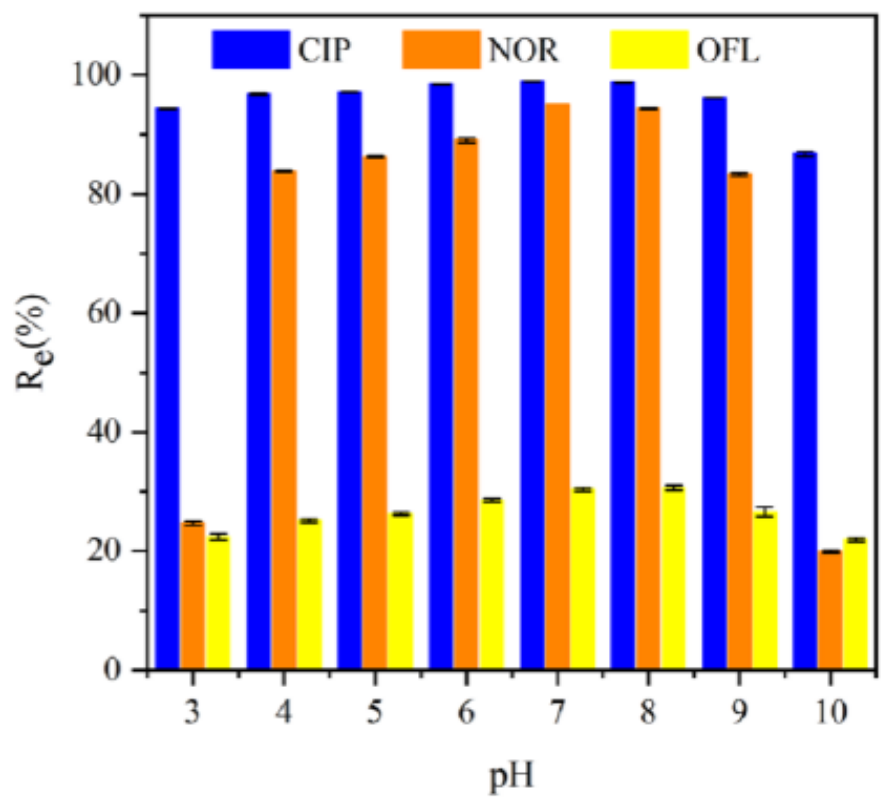

Figure 5

Effect of pH: adsorption capacity (a); removal rate (b). 
(a)

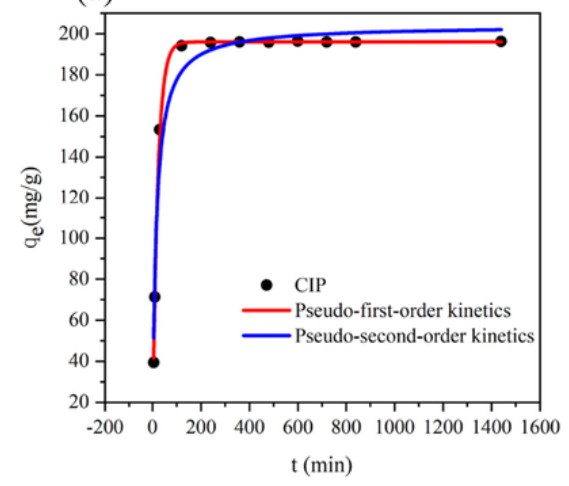

(c)

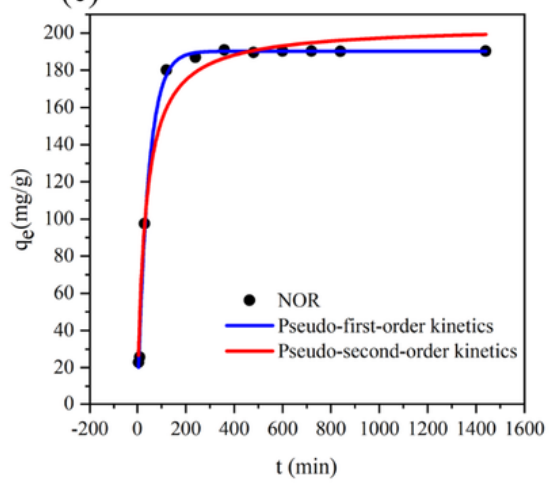

(e)

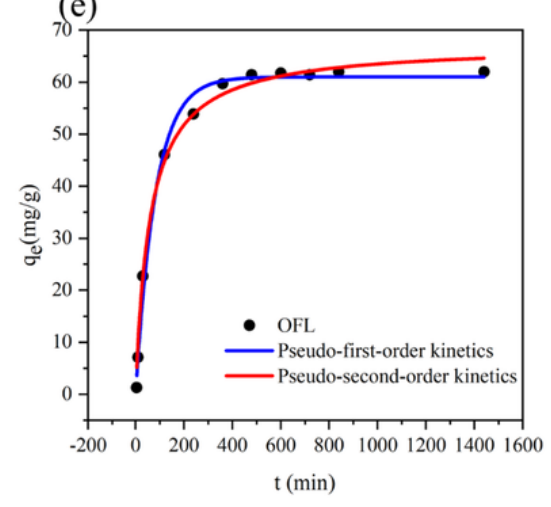

(b)

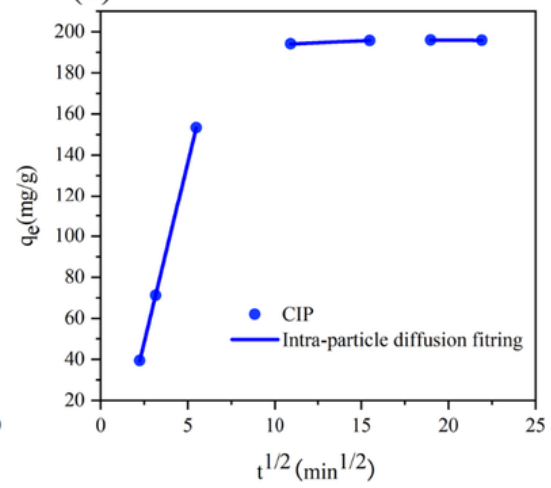

(d)
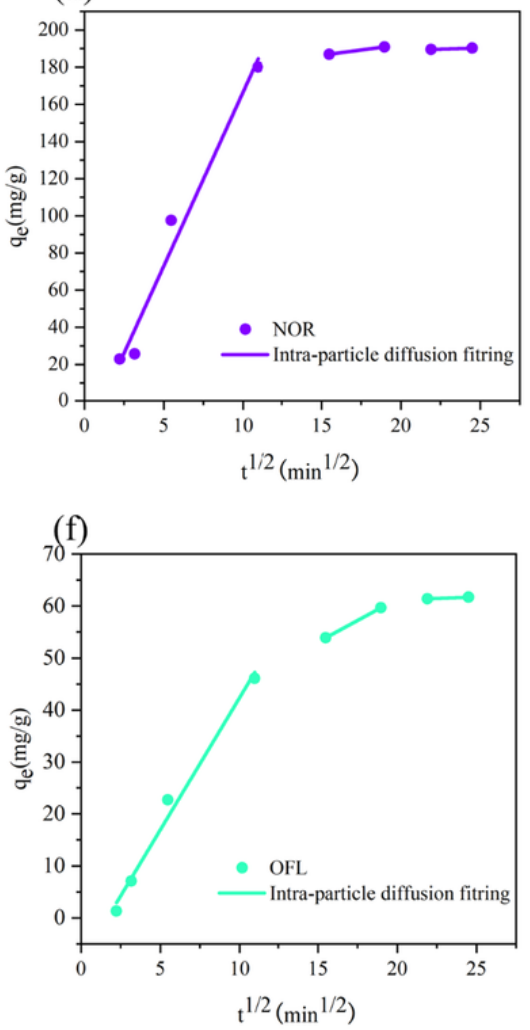

Figure 6

Effect of time for CIP, NOR and OFL adsorption on Ly @ FeZn: the pseudo-first-order fitting plots and pseudo-second-order fitting plots for CIP, NOR and OFL adsorption kinetic model ((a), (c), (e)); the intra-particle diffusion model fitting plots for CIP, NOR and OFL adsorption kinetic model ((b), (d), (f)). 
(a)

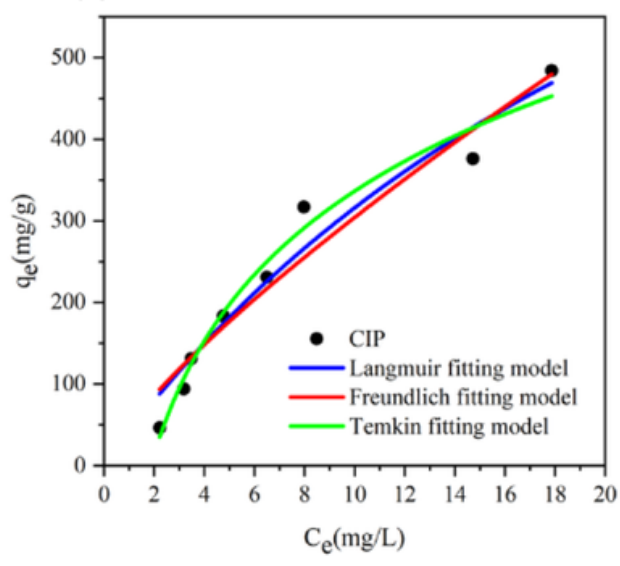

(b)

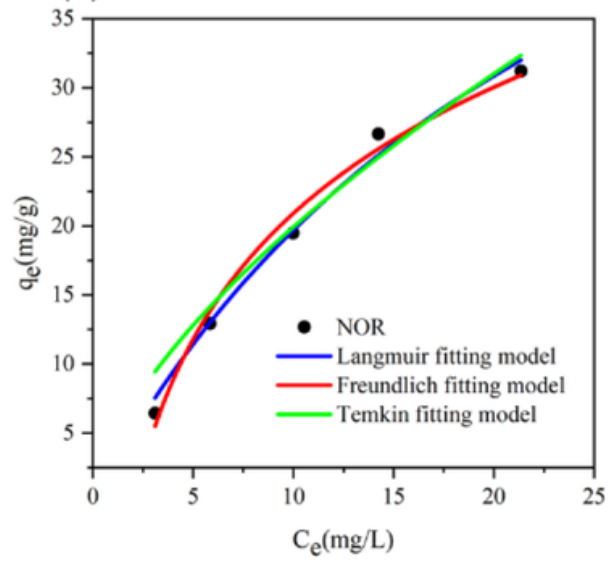

(c)

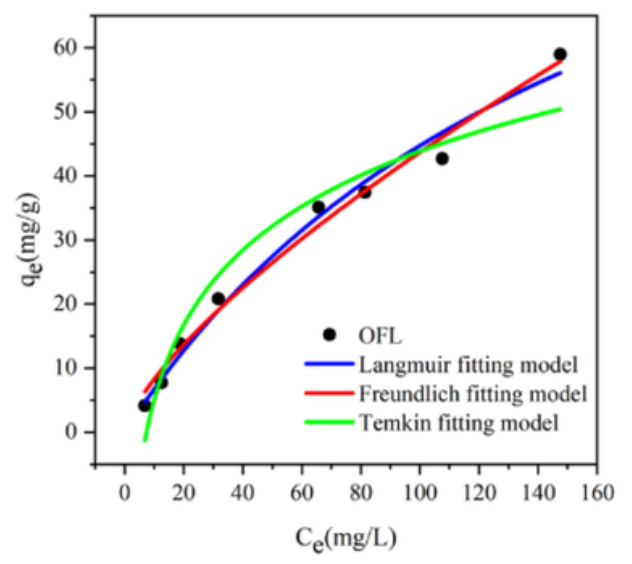

Figure 7

Effect of initial CIP, NOR and OFL concentration on CIP (a), NOR (b) and OFL (c) adsorption on Ly @ FeZn: the fitting plots of Langmuir, Freundlich and Temkin isotherm models. 
(a)

(b)

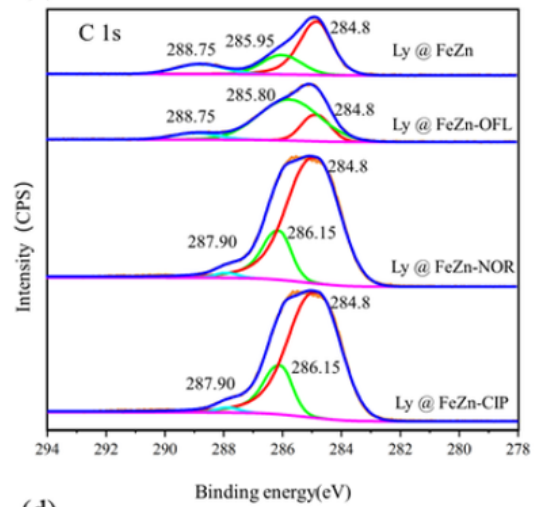

(d)

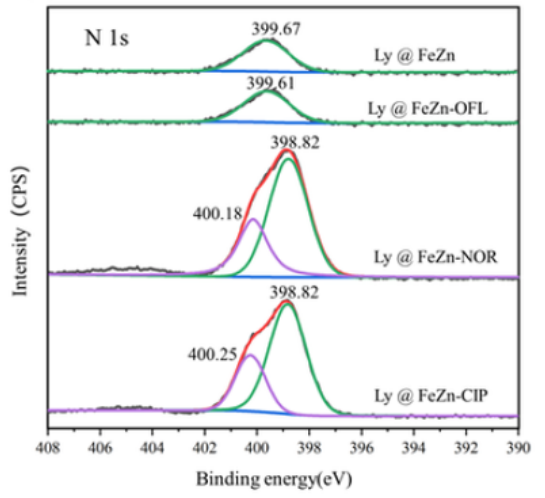

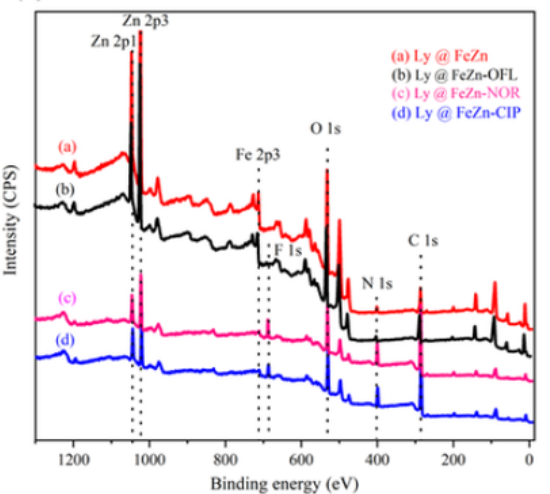

(c)

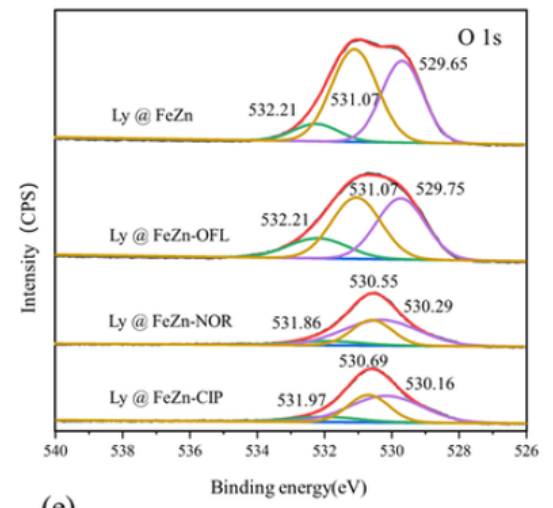

(e)

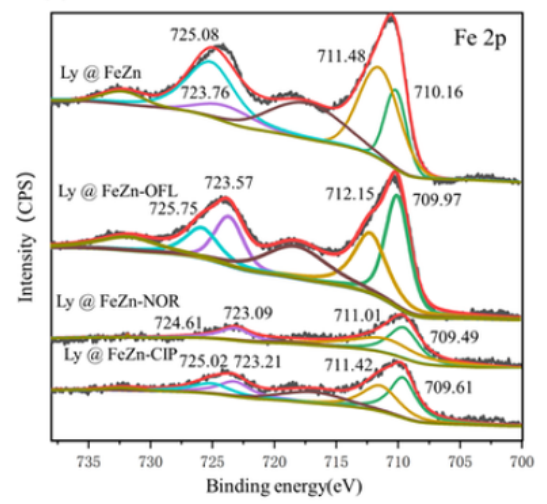

Figure 8

XPS spectra of Ly @ FeZn, Ly @ FeZn-CIP, Ly @ FeZn-NOR and Ly @ FeZn-OFL, full spectra (a); C 1s (b); 0 1s (c); N 1s (d); Fe 2p (e). 


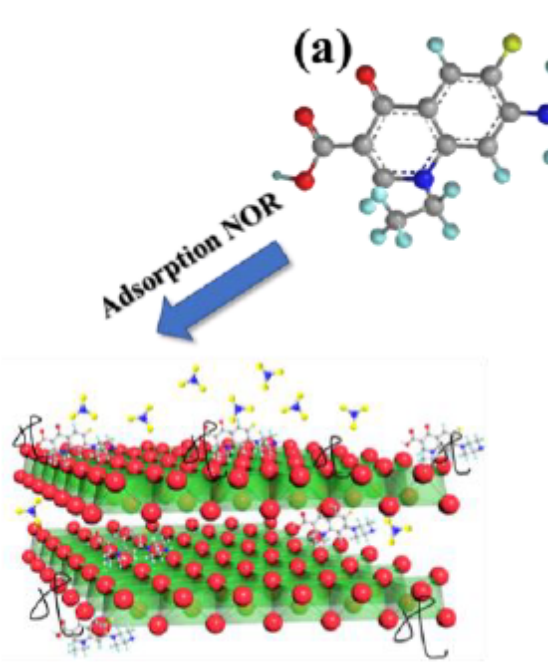

Ly@ FeZn-NOR

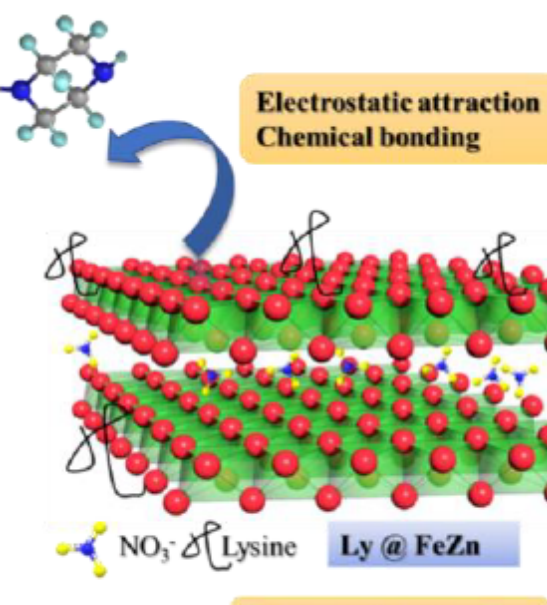

(c)

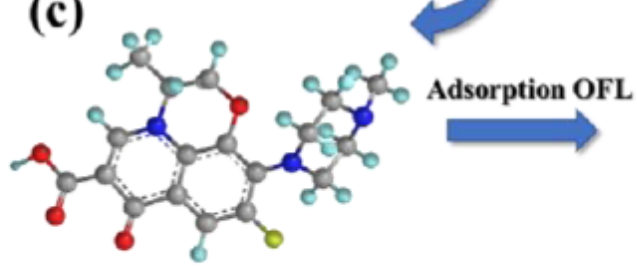

(b)

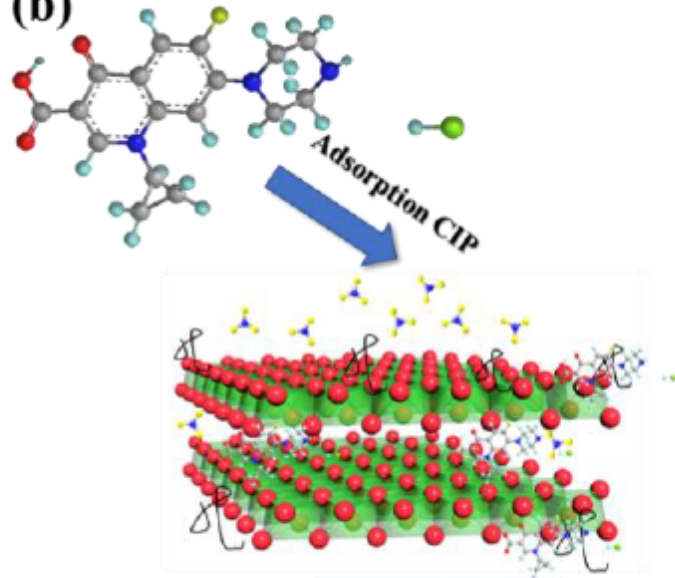

Ly@FeZn-CIP

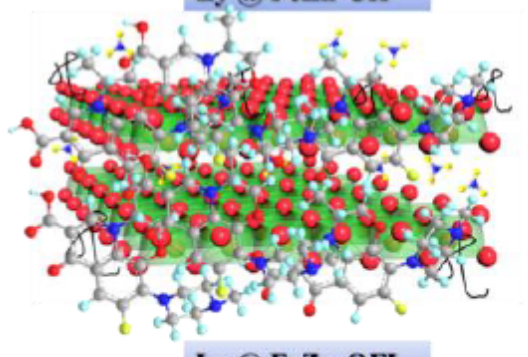

Ly@ FeZn-OFL

Figure 9

Adsorption mechanism diagram. The molecular structure of NOR (a). The molecular structure of CIP (b). The molecular structure of OFL (c).

\section{Supplementary Files}

This is a list of supplementary files associated with this preprint. Click to download.

- SupplementaryMaterial.docx 